\title{
Modulation of $A_{1}$ and $A_{2 B}$ adenosine receptor activity: a new strategy to sensitise glioblastoma stem cells to chemotherapy
}

\author{
S Daniele ${ }^{1,2}$, E Zappelli ${ }^{1,2}$, L Natali $^{1}$, C Martini ${ }^{\star, 1}$ and ML Trincavelli ${ }^{1}$
}

Therapies that target the signal transduction and biological characteristics of cancer stem cells (CSCs) are innovative strategies that are used in combination with conventional chemotherapy and radiotherapy to effectively reduce the recurrence and significantly improve the treatment of glioblastoma multiforme (GBM). The two main strategies that are currently being exploited to eradicate CSCs are (a) chemotherapeutic regimens that specifically drive CSCs toward cell death and (b) those that promote the differentiation of CSCs, thereby depleting the tumour reservoir. Extracellular purines, particularly adenosine triphosphate, have been implicated in the regulation of CSC formation, but currently, no data on the role of adenosine and its receptors in the biological processes of CSCs are available. In this study, we investigated the role of adenosine receptor (AR) subtypes in the survival and differentiation of CSCs isolated from human GBM cells. Stimulation of $A_{1} A R$ and $A_{2 B} A R$ had a prominent anti-proliferative/pro-apoptotic effect on the CSCs. Notably, an $A_{1} A R$ agonist also promoted the differentiation of CSCs toward a glial phenotype. The differential effects of the two AR agonists on the survival and/or differentiation of CSCs may be ascribed to their distinct regulation of the kinetics of ERK/AKT phosphorylation and the expression of hypoxia-inducible factors. Most importantly, the AR agonists sensitised CSCs to the genotoxic activity of temozolomide (TMZ) and prolonged its effects, most likely through different mechanisms, are as follows: (i) by $A_{2 B} A R$ potentiating the pro-apoptotic effects of TMZ and (ii) by $A_{1} A R$ driving cells toward a differentiated phenotype that is more sensitive to TMZ. Taken together, the results of this study suggested that the purinergic system is a novel target for a stem cell-oriented therapy that could reduce the recurrence of GBM and improve the survival rate of GBM patients.

Cell Death and Disease (2014) 5, e1539; doi:10.1038/cddis.2014.487; published online 27 November 2014

Glioblastoma multiforme (GBM), classified as grade IV on the World Health Organization scale, ${ }^{1}$ is the most common type of primary malignant brain tumour. ${ }^{2}$ The current therapeutic strategy includes surgery followed by radiation and chemotherapy using temozolomide (TMZ). This therapeutic approach slightly improves the survival rate of GBM patients, but their prognosis remains poor and most patients die of tumour recurrence. ${ }^{3}$ The causes of the recurrence of GBM are complex and include the high proliferative index of the tumour cells and their resistance to chemotherapy and radiotherapy, particularly in the case of the cancer stem cells (CSCs). These cells have been proposed to not only initiate the genesis of GBM and contribute to its highly proliferative nature, but to also be the basis for its recurrences following treatment. Moreover, it has been reported that the most aggressive or refractory cancers contain the highest number of CSCs. ${ }^{4-6}$

These findings suggest that innovative stem cell-orientated therapy may be an effective strategy to reduce tumour recurrence and significantly improve GBM treatment outcomes. $^{7-18}$ This type of therapy may not be easy to implement because CSCs have been shown to have a low level of reactive oxygen species ${ }^{19}$ and to be more resistant to ionising radiation, ${ }^{20}$ vincristine, ${ }^{21}$ hypoxia and other chemotherapeutics $^{22}$ compared with non-CSCs. In contrast, the preferential elimination of the CSC population may contribute to the effectiveness of $T M Z$, which is the most effective pharmacologic agent used in glioma treatment; ${ }^{23}$ however, the activity of TMZ appears to be short lived because the drug causes the reversible blockage of the cell cycle of CSCs. ${ }^{24}$ Moreover, long-term TMZ therapy results in the occurrence of drug-resistant GBM cells, ${ }^{25}$ indicating the need to develop distinct strategies to overcome this resistance.

Extracellular purines have been implicated in several aspects of GBM biology, such as proliferation, ${ }^{26}$ migration, ${ }^{27}$ invasion ${ }^{28}$ and death. ${ }^{29}$ The concentration of adenosine in the extracellular fluid of glioma tissue was reported to be in the low micromolar range, ${ }^{30}$ which is sufficiently high to stimulate all the four of the adenosine receptor $(A R)$ subtypes $\left(A_{1}, A_{2 A}, A_{2 B}\right.$ and $\left.A_{3}\right) .{ }^{31}$ Each of the ARs have a pivotal role in the control of tumour growth and invasiveness ${ }^{32-34}$ but to date, no data on their role in CSC biology are available. Recently, it was demonstrated that treatment with adenosine triphosphate reduced the rate of sphere formation by glioma cells and that purinergic receptors are differentially expressed in spheres of tumour cells and adherent cells. ${ }^{33}$ In this study, we investigated the role of AR subtypes in the survival and differentiation

\footnotetext{
${ }^{1}$ Department of Pharmacy, University of Pisa, Pisa, Italy

*Corresponding author: C Martini, Department of Pharmacy, University of Pisa, Via Bonanno, 6, Pisa 56126, Italy. Tel: +39 $0502219522-509$; Fax: +39 050 2219609; E-mail: claudia.martini@unipi.it

${ }^{2}$ These authors contributed equally to this work.

Abbreviations: GBM, glioblastoma multiforme; CSCs, cancer stem cells; ARs, adenosine receptors; TMZ, temozolomide

Received 18.6.14; revised 10.10.14; accepted 15.10.14; Edited by R Johnstone
} 
of CSCs. Globally, our data clarified the role of each AR subtype in CSC functionality and suggested that the purinergic system is a novel pharmacological target for the development of new anti-CSC therapies, particularly those aimed at the treatment of GBM recurrences.

\section{Results}

Isolation of the tumour stem cell populations. The formation of neurospheres in vitro in U87MG and U343MG cell cultures was induced by using specific neural stem cell (NSC) medium ${ }^{35}$ (Supplementary Figure 1A). The spheres obtained using either U87MG and U343MG cells included significantly more CD133/nestin ${ }^{+}$cells and a smaller percentage of $\mathrm{GFAP}^{+}$cells compared with the pool of whole GBM cells (Supplementary Figures 1B, C and D).

Expression and functionality of the ARs in GBM cells and CSCs: The expression profiles of the ARs in the GBM cell lines and in their CSCs were compared. Real-time PCR (Figure 1a) and western blot (Figures $1 \mathrm{~b}$ and c) analyses revealed that U87MG and U343MG cells expressed all four of the AR subtypes, as previously reported for other glioma cell lines. ${ }^{36,37}$ The levels of expression of ARs were found to be further increased in CSC-derived neurospheres compared with those of whole GBM cells (Figure 1).

The functional responsiveness of the CSC ARs was evaluated using the GTP $\gamma S$-binding assay. ${ }^{38}$ As shown in Figure 1d, treatment with $\mathrm{CHA}$ and BAY606583 increased the level of GTP $\gamma S$ binding in a concentration-dependent manner, yielding $E_{50}$ values of $6.1 \pm 0.5$ and $1.9 \pm 0.2 \mathrm{nM}$, respectively; these values are comparable to their affinity constant values vis a vis $A_{1} A R$ and $A_{2 B} A R{ }^{39,40}$ In a similar manner, CGS21680 and Cl-IBMECA stimulated GTP $\gamma$ S binding, yielding affinity constant values of $41.9 \pm 4.5$ and $0.46 \pm 0.06 \mathrm{nM}$, respectively, consistent with those previously reported. ${ }^{41,42}$

Effect of AR ligands on CSC proliferation/viability: Incubating U87MG or U343MG cells with the selective AR agonists for 24 or $48 \mathrm{~h}$ did not induce any significant change in the cell proliferation rate (Supplementary Figure 2). After 4 days of $A_{1} A R, A_{2 B} A R$ or $A_{3} A R$ stimulation, the rate of cell proliferation was enhanced (Supplementary Figures $2 A$ and $B$ ), consistent with published data. ${ }^{31}$

Similar experiments were then performed on CSCs: none of AR agonists had a significant effect on the growth of the neurospheres after 24 or $48 \mathrm{~h}$ of treatment (Figures $2 \mathrm{a}$ and $\mathrm{b}$ ). In contrast, when the neurospheres were treated for 4 or 7 days with each of the AR ligands, a significant decrease in cell proliferation was observed (Figures $2 a$ and b). Cell counting showed that all of the AR ligands significantly reduced the percentage of living cells beginning at 4 days of treatment, with a greater effect evident after 7 days of treatment (Supplementary Figure 3). These data suggested that the reduced rate of CSC proliferation can be ascribed, at least partially, to a reduction in the number of living cells.

As similar results on cellular viability were obtained in CSCs isolated from U87MG and U343MG cell lines, the subsequent experiments were focused only on U343MG-derived CSCs, chosen as representative GBM cell line.

Then, a dose-response study of the AR agonists was performed. CHA and BAY606583 induced a concentrationdependent inhibition of CSC proliferation, with a maximal percentage of CSC growth inhibition of $59.9 \pm 1.5$ and $63.6 \pm 7.2$, respectively, and $I_{50}$ values of $11.2 \pm 1.0$ and $3.47 \pm 0.39 \mathrm{nM}$, respectively (Figure $2 \mathrm{c}$ ), the latter being values that are comparable to the degree of affinity of these ligands for the $A_{1} A R$ or $A_{2 B} A R^{39,40}$ In contrast, CGS21680 and $\mathrm{Cl}$-IBMECA had moderate growth-inhibitory effects, with a maximal percentage of CSC growth inhibition of $37.0 \pm 3.5$ and $37.9 \pm 4.2$, respectively (Figure $2 c$ ). The effects of the $A_{1} A R$ and $A_{2 B} A R$ agonists appeared to be completely counteracted by the selective AR antagonists, DPCPX and MRS1754 (Figure 2d), indicating that the anti-proliferative effects of $\mathrm{CHA}$ and BAY606583 on CSCs are specifically mediated by the activation of $A_{1} A R$ and $A_{2 B} A R$, respectively.

We then investigated whether the reduction in cell proliferation elicited by the AR agonists could be associated with cellular apoptosis. Treating the cells for 4 days with BAY606583 induced a slight but significant early apoptosis (Figure $2 \mathrm{e}$ ). In contrast, although a reduction in cell proliferation was demonstrated using the MTS assay (Figure 2d), CHA did not induce cellular apoptosis at this point of treatment (Figures 2e and f). After 7 days, both CHA and BAY606583 induced a significant level of phosphatidylserine externalisation, both without (early apoptosis) and with the occurrence of 7-amino-actinomysin 11 binding to DNA (late apoptosis/ death) (Figures $2 e$ and f), with a total percentage of cellular apoptosis of $52.0 \pm 0.6$ and $56.3 \pm 2.6$, respectively. These data are consistent with the reduction in the percentage of living cells revealed using the Trypan blue exclusion assay (Supplementary Figure 3). Treatment with CGS21680 and CI-IBMECA significantly induced early stage of CSC apoptosis, with total percentages of apoptotic cells of $18.8 \pm 1.5$ and $19.4 \pm 1.8$, respectively (Supplementary Figure 4), confirming that stimulating $A_{2 A} A R$ and $A_{3} A R$ had only moderate effects on CSC viability/apoptosis.

Effects of $A_{1} A R$ and $A_{2 B} A R$ agonists on the morphology and differentiation of CSCs: As the most promising anti-proliferative effects of the AR agonists were obtained using $\mathrm{CHA}$ and BAY606583, the roles of the $A_{1} A R$ and $A_{2 B} A R$ subtypes in CSCs were further investigated. The effects of selective $A_{1}$ or $A_{2 B} A R$ agonists on CSC morphology were thus evaluated.

After 7 days of treatment, BAY606583 caused a significant reduction in the area occupied by the cells and the number of neurospheres (Figure 3). These effects were observed after 4 days of treatment, although to a lesser extent (Supplementary Figure 5).

When CSCs were incubated with CHA for 4 days, an increase in the number of adherent cells was observed, and the CSCs began to exhibit cellular processes (Supplementary Figure 5). After 7 days of treatment, an almost loss of floating spheres was noticed (Figures $3 a$ and d) and the cells exhibited significant outgrowth of processes. Comparing these data with those obtained in the Annexin V-staining assay suggested that CHA first induced CSC differentiation and, in a later phase, triggered the apoptosis of the differentiated cells. 
a
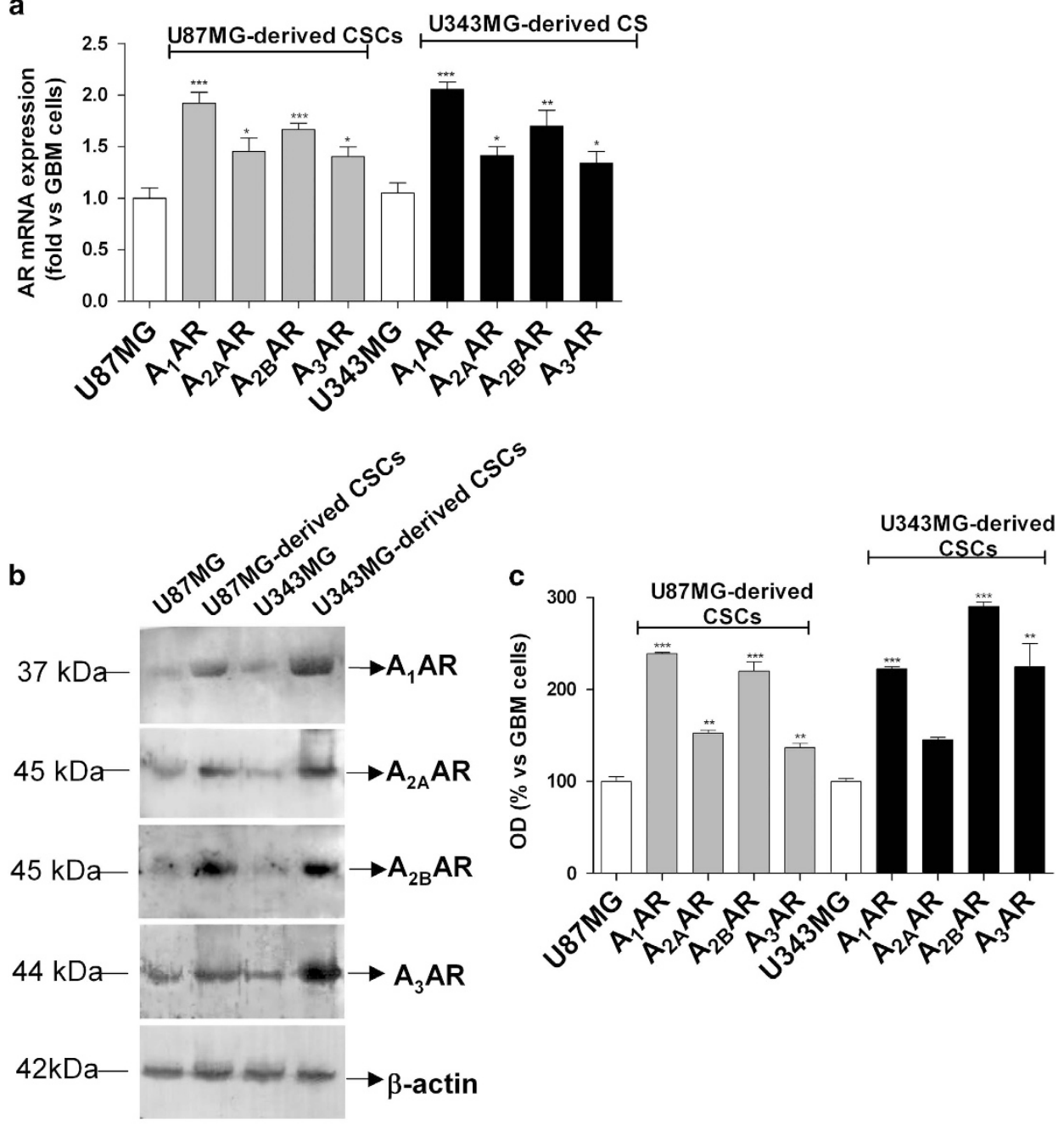

d

U343MG-derived CSCs

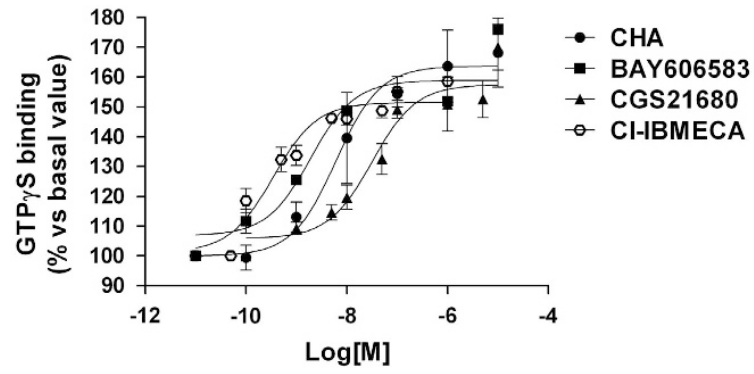

Figure 1 Expression of ARs in CSCs derived from U87MG and U343MG cells. (a) The total RNA was extracted from whole U87MG cells and U343MG cells and from the respectively derived CSCs. The relative quantification of the AR subtype mRNAs was performed using real-time RT-PCR, as described in the Materials and methods section. The data were expressed as the fold change relative to the level of expression of each AR subtype in GBM cells (each set to 1) and they are the mean values \pm S.E.M. of three different experiments. ( $(\mathbf{b}$ and $\mathbf{c}$ ) Cell lysates were prepared from whole U87MG cells, U343MG cells and the CSCs derived from them. The AR protein levels were evaluated using western blot analysis, using $\beta$-actin as the loading control. (b) Representative western blots. (c) Densitometric analysis of the immunoreactive bands performed using the ImageJ program. The data were expressed as the percentage relative to the level of expression in whole GBM cells, and they are the mean values \pm S.E.M. of three different experiments. The significance of the differences was evaluated using a one-way ANOVA with the Bonferroni post-test: ${ }^{*} P<0.05,{ }^{* \star} P<0.01,{ }^{* \star *} P<0.001$ versus the levels of expression in whole GBM cells. (d) ${ }^{35}$ S]GTP $\gamma$ S binding of U343MG-derived CSCs. Membrane aliquots $(30 \mu \mathrm{g})$ obtained from CSCs were incubated with the indicated selective AR agonists at various concentrations. All of the data were expressed as the percentages of the level of basal $\left[{ }^{35} \mathrm{~S}\right] \mathrm{GTP} \gamma \mathrm{S}$ binding (set to $\left.100 \%\right)$, and they are the mean values \pm S.E.M. of three different experiments, each performed in duplicate 
The receptor specificity of the CHA- and BAY606583mediated effects was confirmed using the selective antagonists DPCPX and MRS1754 (Supplementary Figure 6).

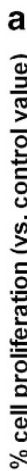

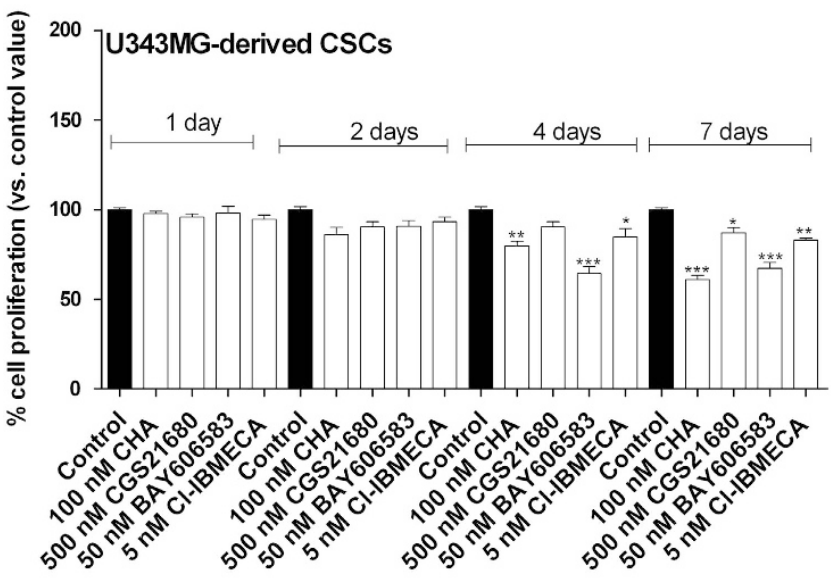

C

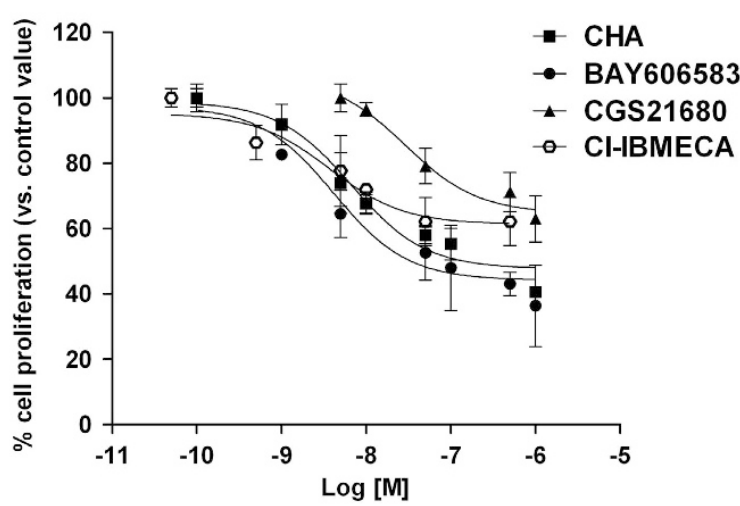

To further investigate the mechanisms through which $\mathrm{CHA}$ and BAY606583 affected CSC morphology, we then assessed the expression of stem cell and differentiation markers in

b

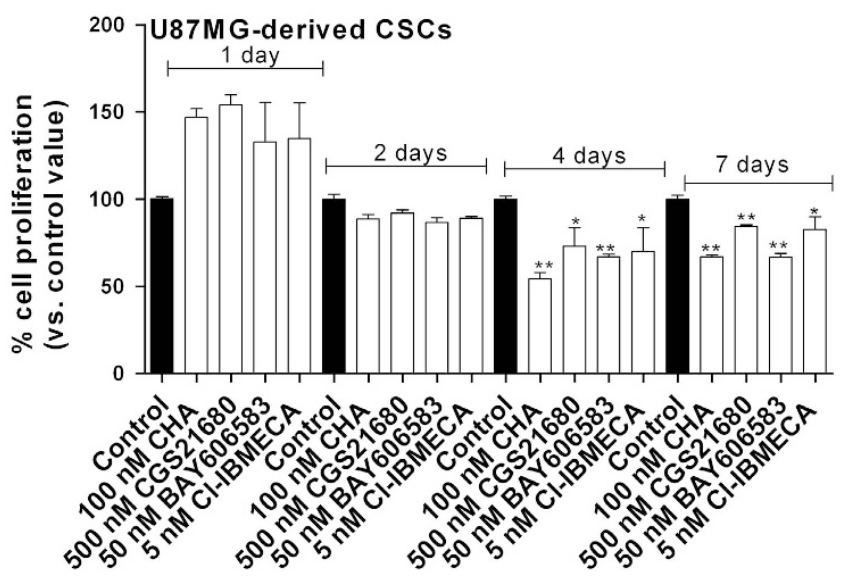

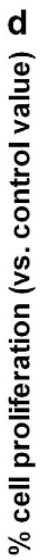

e
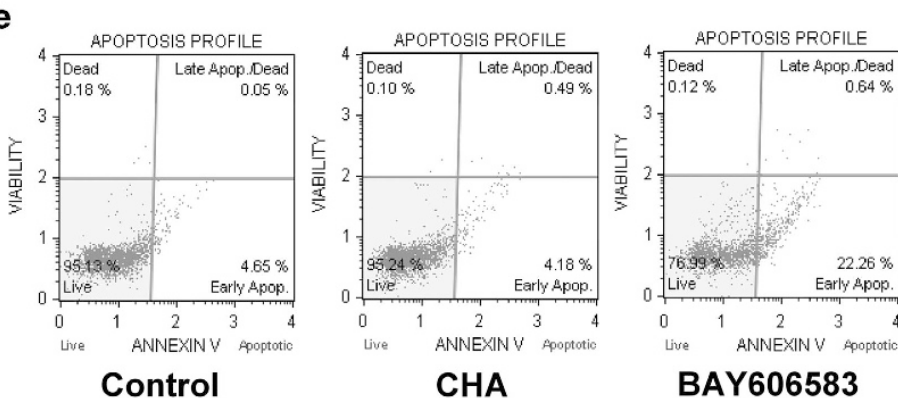

BAY606583

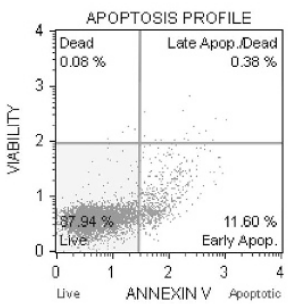

Control

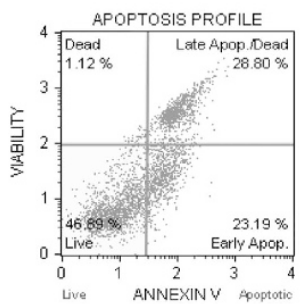

CHA

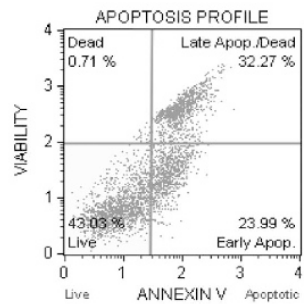

BAY606583

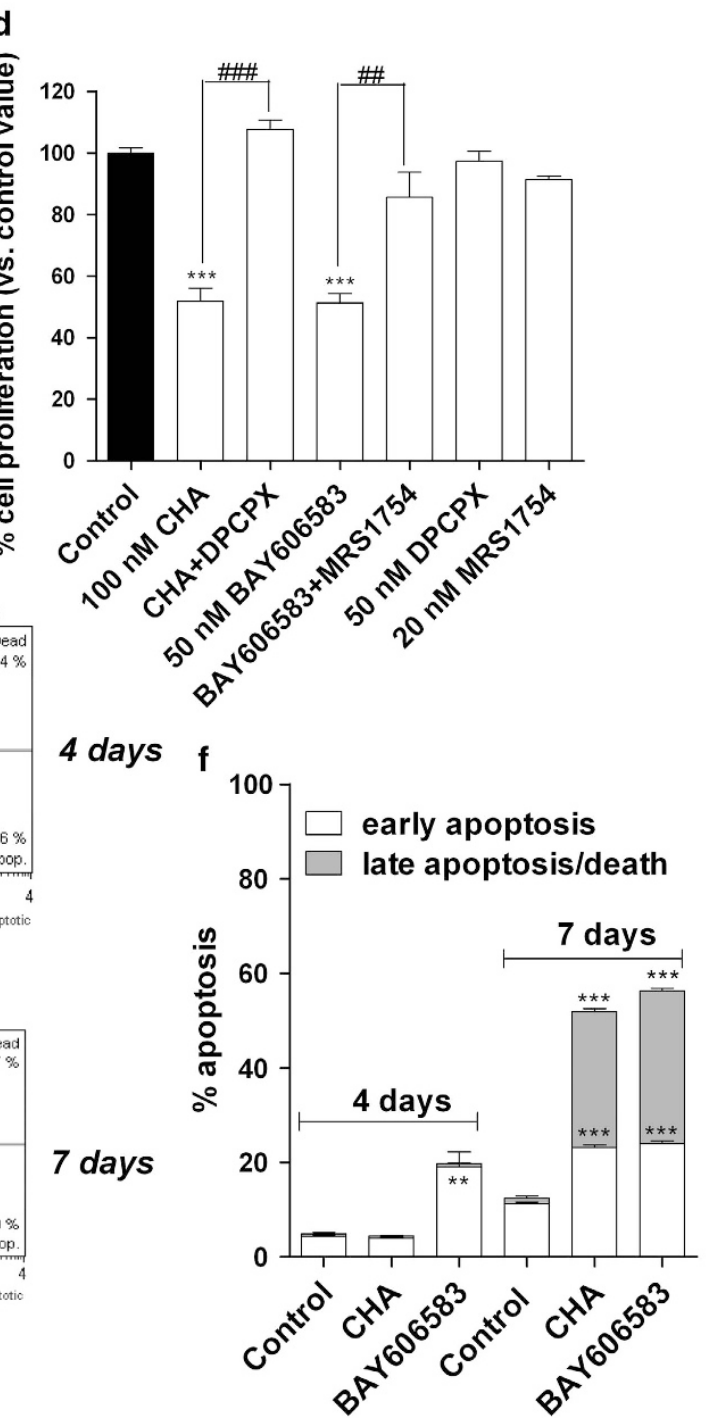


CSCs upon their stimulation with these agonists. Real-time PCR (Figure 4a) and western blot analysis (Figures 4b and c) revealed that BAY606583 did not significantly affect the levels of expression of stem cell markers and of the astrocyte marker, suggesting that stimulation of $\mathrm{A}_{2 \mathrm{~B}} \mathrm{AR}$ did not change the CSC phenotype. In comparative studies, no alteration of the CSC phenotype was observed with either CGS21680 or Cl-IBMECA treatment (Supplementary Figure 7). In contrast, in CHA-treated CSCs, a significant decrease in the expression of the stemness markers (Figure 4) and a significant increase in the expression of GFAP and Olig2 was observed, demonstrating that $\mathrm{CHA}$ promoted CSC differentiation toward a glial phenotype.

Next, we assessed whether CHA- or BAY606583-treated cells could resume growing after the removal of the drug. After the BAY 606583 challenge and a wash-out period of 7 or 14 days, spheres began to resume proliferation (Figures $3 a-c$ ). In contrast, the CHA-treated cells retained their differentiated morphology even after 14 days of drug wash-out, although some floating spheres were observed (Figures 3a-d). These results were confirmed using the MTS assay (Figure 3e).

Effects of the $A_{1} A R$ and $A_{2 B} A R$ agonists on pro-apoptotic/ differentiating pathways: Different signalling pathways have been demonstrated to have a pivotal role in CSC selfrenewal, migration and differentiation, ${ }^{43}$ including the phosphatidylinositol 3-kinase (PI3K)/AKT and the MEK/ERK pathways. ${ }^{44}$ Thus, the effects of the $A_{1} A R$ and $A_{2 B} A R$ agonists on the levels of total and phosphorylated ERK1/2 and AKT were first investigated. CSC incubation with AR agonists did not alter total ERK or AKT levels (Supplementary Figure 8). Both CHA and BAY 606583 induced a modest but significant inhibition of ERK1/2 phosphorylation, which persisted for the 30 min of CSC incubation (Figure 5a). Both ligands also affected the $\mathrm{p}$-AKT level, although with a different kinetic pattern; whereas CHA inhibited AKT phosphorylation for up to $30 \mathrm{~min}$, BAY606583 caused only a transient blockage of AKT phosphorylation (Figure 5b), suggesting that the kinetics of AKT inhibition may explain the different effects of the two AR agonists.

Several studies have demonstrated that hypoxia-inducible factors (HIFs), including HIF- $1 a$ and HIF-2a, have potential biological effects on maintaining the stemness of these cells. ${ }^{45-49}$ Therefore, the modulation of HIF transcriptional activity upon incubation with the $A_{1}$ or $A_{2 B} A R$ agonists was investigated. Neither of ligands altered the HIF-1a level after 4 days of treatment, whereas both of them caused a significant reduction in the HIF-1a level after 7 days of treatment (Figure 5c), consistent with the marked inhibition of CSC proliferation at this time point. ${ }^{50-52}$

BAY606583 treatment did not affect the level of HIF-2a mRNA at the analysed time points; in contrast, CHA caused a slight but significant reduction in the level of HIF-2a mRNA by 4 days of treatment (Figure $5 \mathrm{c}$ ), consistent with the reduction in the levels of expression of the stem cell markers caused by its differentiation-promoting effects. Interestingly, 7 days of CHA treatment enhanced the HIF-2a transcriptional activity, indicating that a different HIF-2a-mediated mechanism may be in effect in CHA-differentiated CSCs. We then investigated whether the AR ligands modulated the expression of the apoptosis regulator Bax, a member of $\mathrm{Bcl}-2$ protein family, ${ }^{53}$ and of the executioner protein caspase-3, responsible for biochemical and morphological hallmarks of apoptosis. ${ }^{54}$

BAY606583 induced a significant enhancement of the Bax mRNA level starting at 4 days of treatment, with a maximal effect at the 7th day (Figure 5c). In contrast, $\mathrm{CHA}$ increased Bax transcriptional activity only after 7 days of treatment (Figure $5 d$ ). At this latter time point, both agonists had also induced a significant level of caspase-3 cleavage (Figures $5 \mathrm{e}$ and f).

Combined effect of the $A_{1} / A_{2 B} A R$ ligands and $T M Z$ on CSCs: Considering that TMZ is the most effective pharmacologic agent used in glioma treatment and has partial and reversible effects on CSCs, ${ }^{25,55}$ the effect of a combined treatment with $T M Z$ and the $A_{1} A R$ or $A_{2 B} A R$ ligand on the survival of CSCs was then examined. TMZ alone significantly inhibited CSC proliferation (Figure 6a), as previously demonstrated. ${ }^{24}$ Treatment for 7 days with $\mathrm{TMZ}$ plus $\mathrm{CHA}$ or with TMZ plus BAY606583 had a synergic/additive effect on the reduction of neurosphere growth (Figure 6a), most likely due to a reduction in the level of cell viability (Supplementary Figure 9).

Consistent with these data, when the alkylating agent was applied in combination with CHA or BAY606583, a significant enhancement of the level of late-stage cellular apoptosis was observed (Figures $6 \mathrm{~b}$ and $\mathrm{c}$ ).

To further investigate the effects of such combined therapies, a morphological analysis was performed. TMZ alone significantly decreased both the area occupied by and the number of neurospheres present at 7 days (Figure 7). However, after 14 days of drug wash-out, the TMZ-treated cells recovered their normal cell growth, as confirmed by the MTS assay (Figure 7d).

Figure 2 Effects of AR agonists on CSC proliferation. U343MG-derived CSCs (a) or U87MG-derived CSCs (b) were treated for the indicated number of days with the $A_{1} A R$ agonist (CHA), the $A_{2 A} A R$ agonist (CGS21680), the $A_{2 B} A R$ agonist (BAY606583) or the $A_{3} A R$ agonist Cl-IBMECA at selected concentrations (corresponding to tenfold the values of the affinity constants). (c) CSCs derived from U343MG cells were incubated for 7 days with the AR agonists at increasing concentrations. (d) CSCs derived from U343MG cells were incubated for 7 days with $100 \mathrm{nM}$ CHA, in the absence or in the presence of the $A_{1} A R$ antagonist DPCPX (50 nM), or with $50 \mathrm{nM}$ BAY606583, in the absence or in the presence of the $A_{2 B} A R$ antagonist MRS1754 $(20 \mathrm{nM})$. At the end of the treatments, cell proliferation was evaluated using the MTS assay. The data were expressed as a percentage with respect to that of untreated cells (control), which was set to $100 \%$, and they are the mean values \pm S.E.M. of three independent experiments, each performed in duplicate. (e and f) CSCs were treated for 4 or 7 days with NSC medium containing DMSO (control), $100 \mathrm{nM} \mathrm{CHA} \mathrm{or} 50 \mathrm{nM} \mathrm{BAY606583.} \mathrm{At} \mathrm{the} \mathrm{end} \mathrm{of} \mathrm{treatments,} \mathrm{the} \mathrm{cells} \mathrm{were}$ collected and the degree of phosphatidylserine externalisation was evaluated using the Annexin V protocol, as described in the Materials and method section. (f) The data were expressed as the percentage of apoptotic cells (early-stage apoptotic cells shown in white, late-stage apoptotic/necrotic cells shown in grey) relative to the total number of cells. The data shown are the mean values \pm S.E.M. of three different experiments. The significance of the differences was determined using a one-way ANOVA with the Bonferroni post-test. ${ }^{*} P<0.05,{ }^{* *} P<0.01,{ }^{* * *} P<0.001$ versus control. ${ }^{\# \#} P<0.01,{ }^{\# \# \#} P<0.001$ versus agonist alone 
When combined, TMZ and BAY606583 exerted a synergic/ additive effect on inhibiting the proliferation of CSCs and significantly decreased the ability of the cells to resume proliferation (Figure 7). Interestingly, in the presence of TMZ, $\mathrm{CHA}$ did not induce CSC differentiation but rather had a synergic/additive effect on reducing the rate of cell proliferation

A

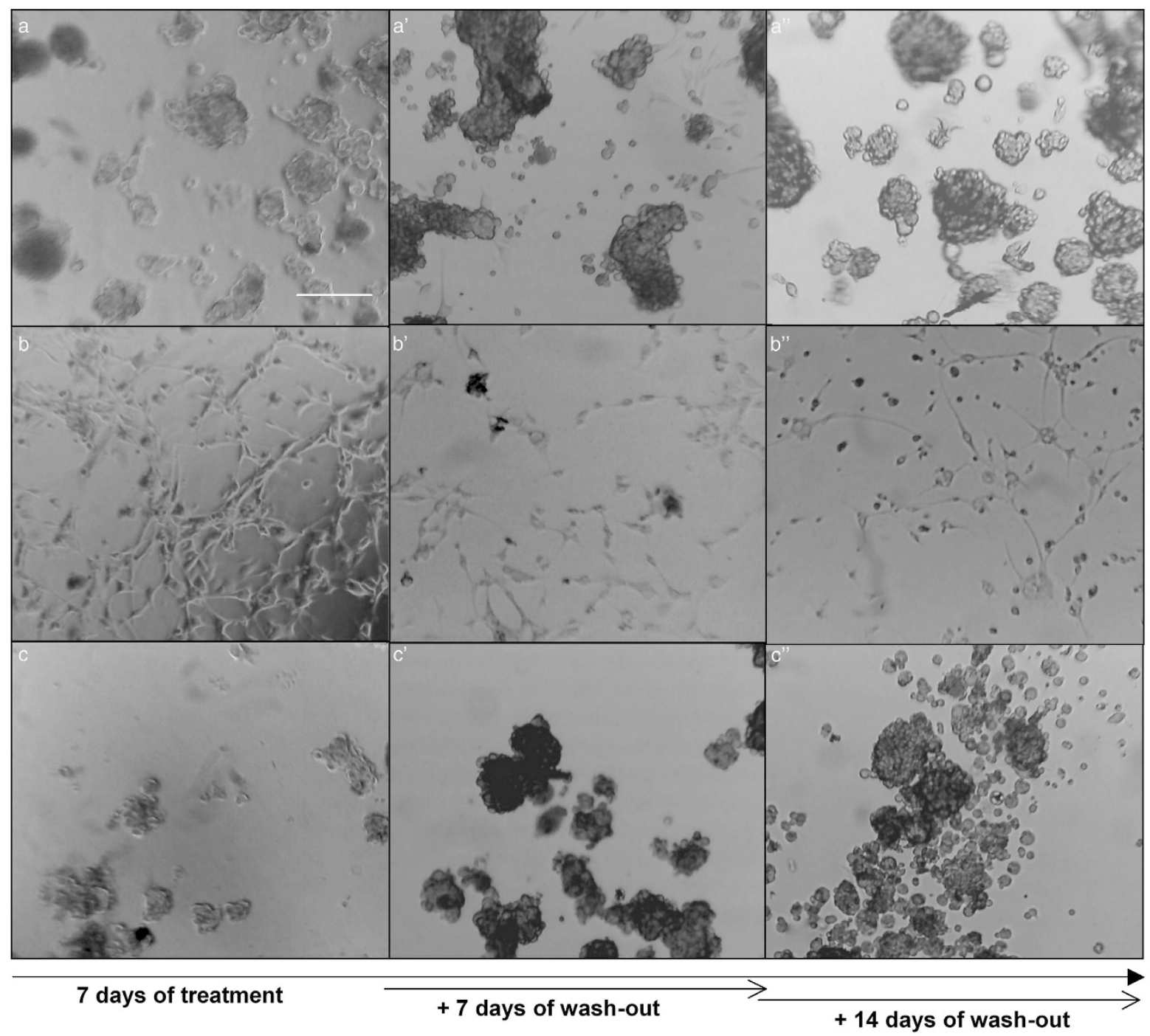

B

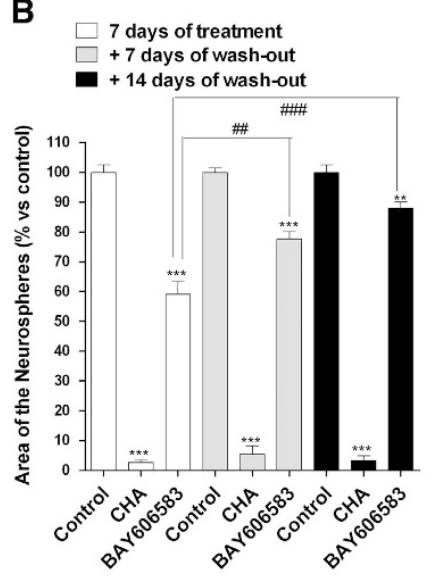

C

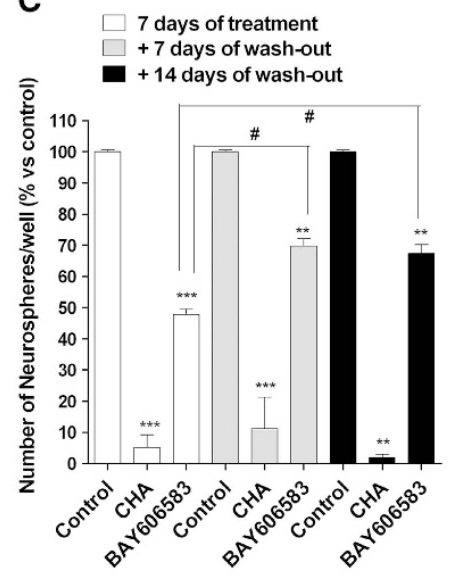

D

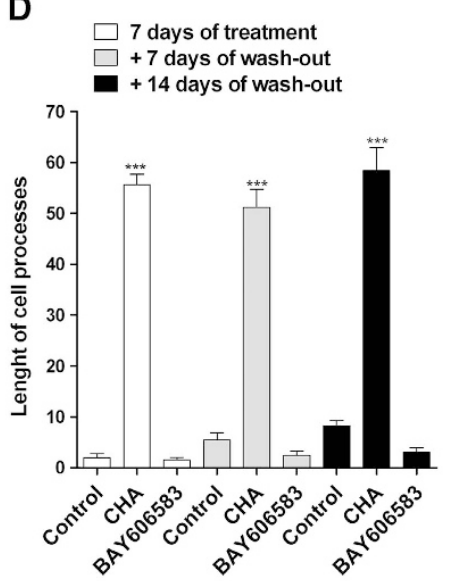

E

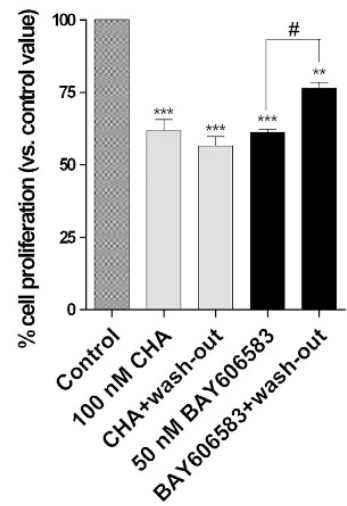


relative to that of TMZ-treated cells (Figure 7). Moreover, a significant decrease in the ability of the cells to resume growth was noticed (Figures $7 a-d)$.

The effects of the sequential treatment of CSCs with an AR agonist and $T M Z$ were also investigated. A prior challenge with BAY606583 enhanced the chemotherapeutic effect of TMZ (Figure 8): the percentage of reduction of both the area occupied by and the number of CSC-derived neurospheres was significantly higher in the BAY606583-TMZ-treated cells than in the cells treated with $\mathrm{TMZ}$ alone $(\%$ of reduction of the area occupied by the neurospheres: $\mathrm{TMZ}$ alone $=57.3 \pm$ 4.3\%; BAY606583-TMZ $=70.2 \pm 0.6 \% ; P<0.001)$. Moreover, the ability of the BAY606583-TMZ-treated cells to resume growth at 14 days of wash-out was significantly lower than that of TMZ-treated cells (\% of reduction of the area occupied by the neurospheres: $\mathrm{TMZ}$ alone $=36.1 \pm 3.4 \%$; BAY606583$\mathrm{TMZ}=82.6 \pm 4.1 \% ; P<0.001)$. These data were confirmed by the MTS assay (Figure $8 d$ ).
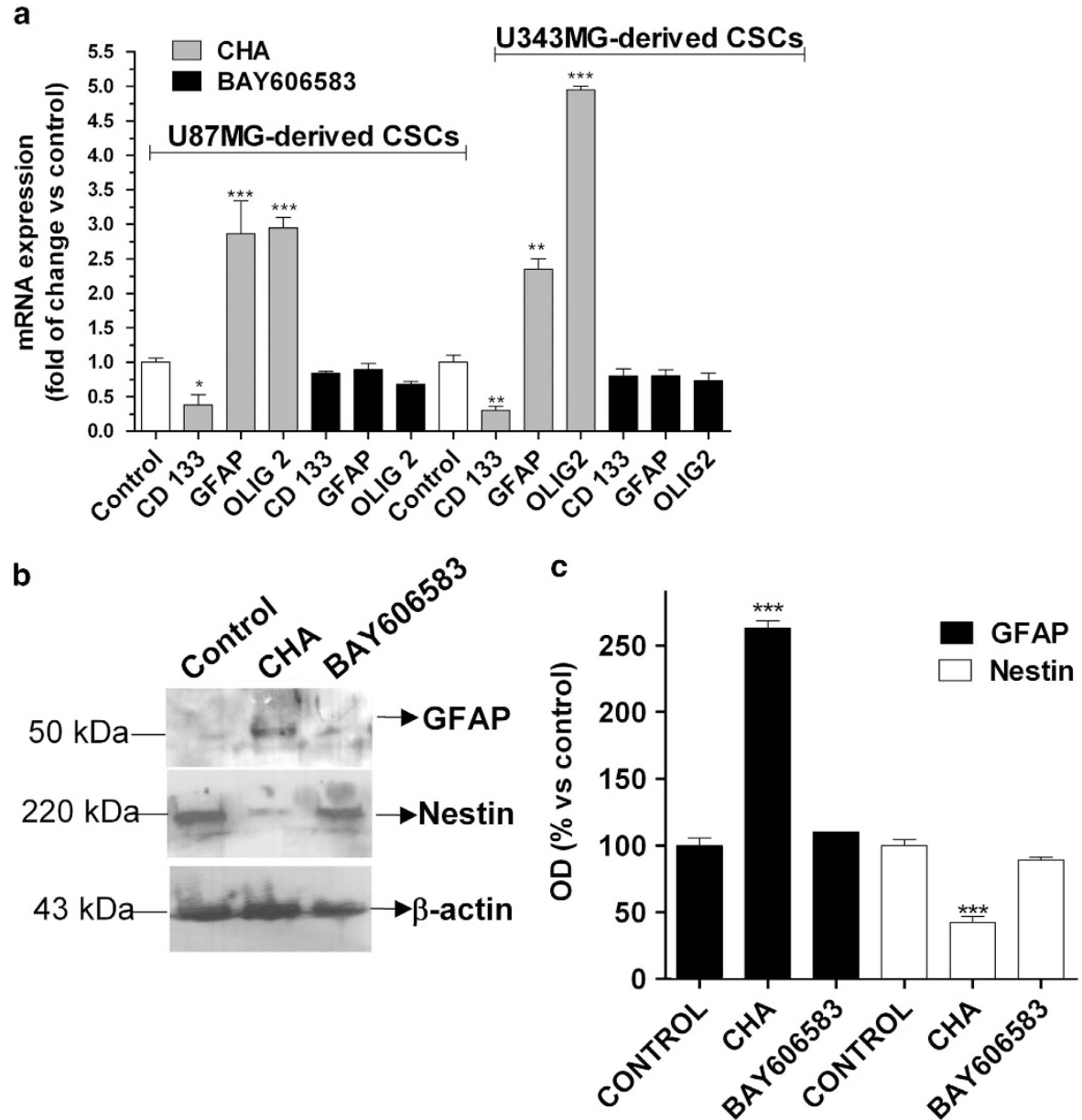

Figure 4 Effects of $A_{1} A R$ and $A_{2 B} A R$ agonists on the expression of differentiation and stemness markers in CSCs. (a) CSCs derived from U87MG or U343MG cells were treated for 7 days with NSC medium containing DMSO (control), $100 \mathrm{nM} \mathrm{CHA} \mathrm{or} 50 \mathrm{nM} \mathrm{BAY606583.} \mathrm{At} \mathrm{the} \mathrm{end} \mathrm{of} \mathrm{treatment} \mathrm{periods,} \mathrm{the} \mathrm{total} \mathrm{RNA} \mathrm{was} \mathrm{extracted,} \mathrm{and} \mathrm{relative}$ quantification of the mRNAs for the stem cell marker CD133, the astrocyte marker GFAP, and the oligodendrocyte marker Olig2 were performed using RT-PCR, as described in the Materials and methods section. The data were expressed as the fold change versus the levels of the control and they are the mean values \pm S.E.M. of three different experiments. ( $\mathbf{b}$ and $\mathbf{c}$ ) CSCs from U343MG cells were treated as in $\mathbf{a}$; at the end of treatment periods, cell lysates were subjected to western blot analysis using antibodies specific for the stem cell marker nestin or the glial-cell marker GFAP. (b) Representative western blots. (c) The bar graph shows the results of the quantitative analysis of the western blots, which was performed using the ImageJ program. The data were expressed as the percentage of optical density of the immunoreactive band relative to that of the control, set to $100 \%$ and are the mean values \pm S.E.M. of three different experiments. The significance of the differences was determined using a one-way ANOVA with the Bonferroni post-test: ${ }^{*} P<0.05,{ }^{* *} P<0.01,{ }^{* * *} P<0.001$ versus control

Figure 3 Effect of $A_{1} A R$ and $A_{2 B} A R$ agonists on the sphere-derived cell morphology of the CSC-derived cellular spheres. CSCs were treated for 7 days with complete NSC medium containing DMSO (control, a), $100 \mathrm{nM} \mathrm{CHA} \mathrm{(b)} \mathrm{or} 50 \mathrm{nM} \mathrm{BAY606583} \mathrm{(c).} \mathrm{At} \mathrm{the} \mathrm{end} \mathrm{of} \mathrm{treatment} \mathrm{periods,} \mathrm{the} \mathrm{drug-containing} \mathrm{media} \mathrm{were} \mathrm{replaced} \mathrm{with} \mathrm{fresh} \mathrm{drug-free}$ NSC medium, and cells were cultured for another $7\left(a^{\prime}, b^{\prime}, c^{\prime}\right)$ or 14 days $\left(a^{\prime \prime}, b^{\prime \prime}, c^{\prime \prime}\right.$ ). (A) Representative micrographs taken after 7 days of treatment and after 7 or 14 days of drug wash-out are shown. The area of the culture plates occupied by the spheres (B), the number of spheres (C) and the length of the cellular processes (D) were scored after 7 days of treatment and after 7 and 14 days of drug wash-out. The counts represent the mean values \pm S.E.M. of three independent experiments. (E) CSCs were treated as in $\mathbf{A}$, and cell proliferation was evaluated using the MTS assay. The data were expressed as percentages relative to that of the untreated cells (control), which was set at $100 \%$, and they are the mean values \pm S.E.M. of three independent experiments, each performed in duplicate. The significance of the differences was determined using a one-way ANOVA with the Bonferroni post-test: ${ }^{* \star} P<0.01,{ }^{* \star *} P<0.001$ versus control; ${ }^{\#} P<0.05,{ }^{\# \#} P<0.01,{ }^{\# \# \#} P<0.001$ versus cells treated for seven days 
In a similar way, after CHA-induced CSC differentiation occurred, the effect of TMZ on cell proliferation was significantly stronger (Figures $8 \mathrm{a}-\mathrm{d}$ ). Notably, when TMZ

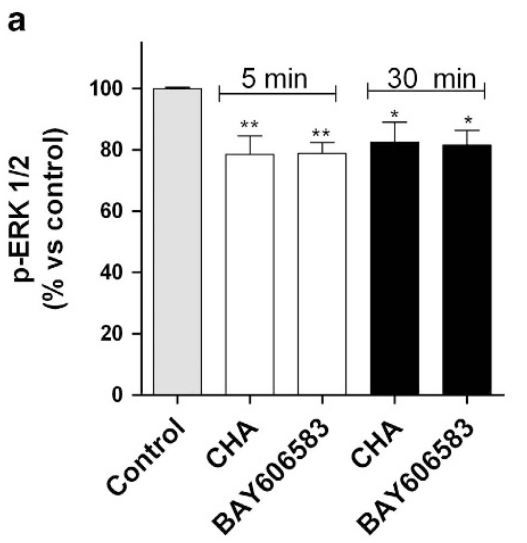

c

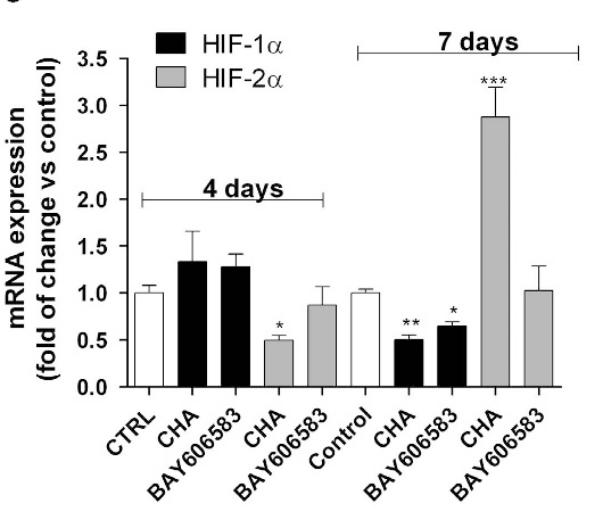

e

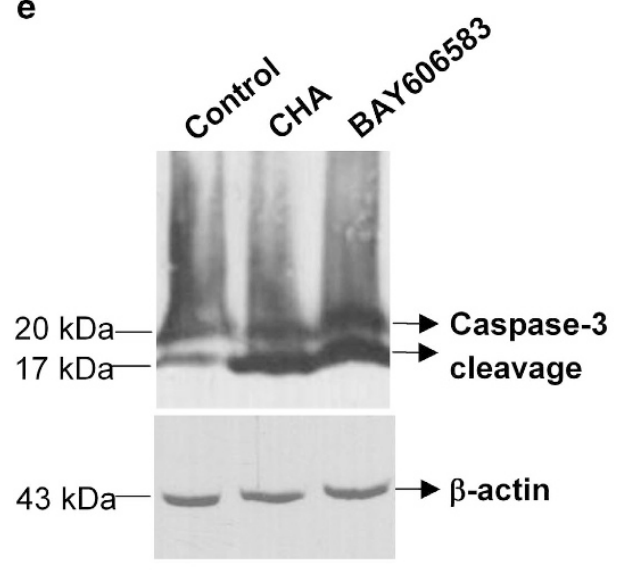

was applied to cells that had been induced to differentiate by $\mathrm{CHA}$ treatment, the number of cells per well was decreased and was further decreased after 14 days of drug wash-out
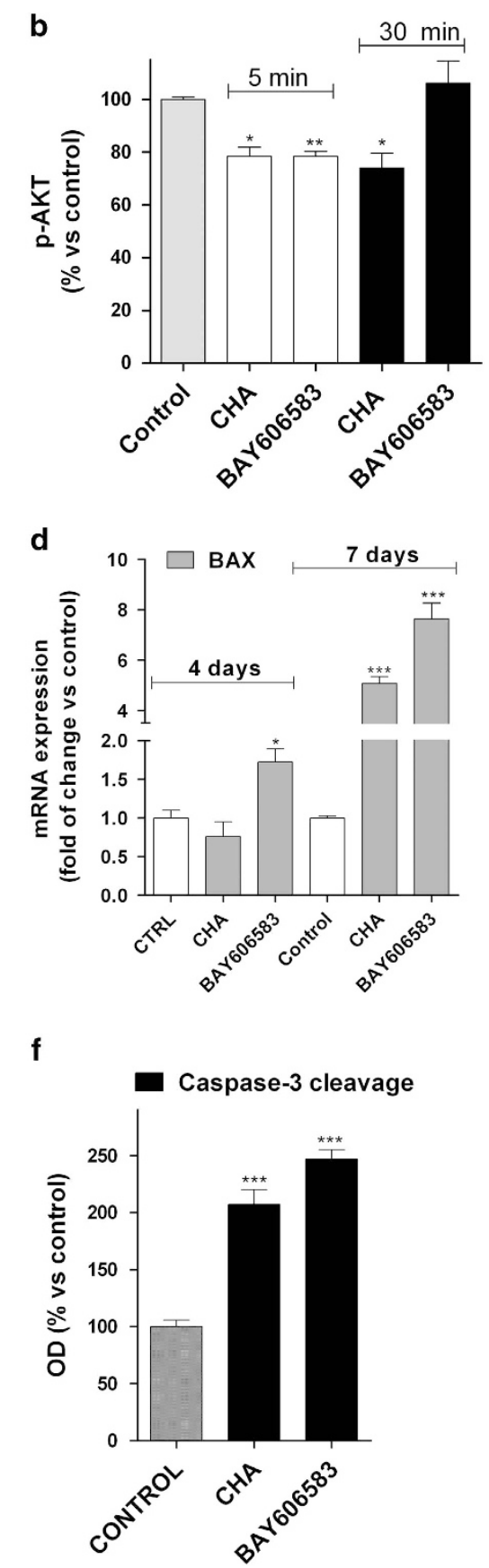

Figure 5 Effects of $A_{1} A R$ and $A_{2 B} A R$ agonists on pro-apoptotic/differentiating pathways. (a and $\mathbf{b}$ ) U343MG-derived CSCs were treated for 5 or 30 min with complete medium containing DMSO (control), $100 \mathrm{nM} \mathrm{CHA} \mathrm{or} 50 \mathrm{nM}$ BAY606583. Following the treatments, the levels of ERK 1/2 (a) and AKT (b) phosphorylation were evaluated using ELISA kits, as described in the Materials and methods section. The data were expressed as the percentage of phosphorylated AKT or ERK1/2 relative to those of untreated cells (control), which were set at $100 \%$, and are the mean values \pm S.E.M. of three independent experiments performed in triplicate. (c and d) CSCs derived from U343MG cells were treated for 4 or 7 days with NSC medium containing DMSO (control), $100 \mathrm{nM} \mathrm{CHA} \mathrm{or} 50 \mathrm{nM} \mathrm{BAY606583.} \mathrm{At} \mathrm{the} \mathrm{end} \mathrm{of} \mathrm{the} \mathrm{treatment} \mathrm{periods,} \mathrm{the} \mathrm{total} \mathrm{RNA} \mathrm{was} \mathrm{extracted,} \mathrm{and} \mathrm{the} \mathrm{relative}$ quantification of the HIFs (c) and Bax (d) mRNAs was performed using RT-PCR. The data were expressed as the fold change versus the level of the control and are the mean values \pm S.E.M. of three different experiments. (e and f) CSCs derived from U343MG cells were treated as in a for 7 days. The cell lysates were subjected to western blot analysis using an antibody specific for caspase-3 cleavage products. (e) Representative western blots. (f) The bar graph shows the results of the quantitative analysis of the western blots, which was performed using the ImageJ program. The data were expressed as the percentage of optical density of the immunoreactive band relative to that of the control, set to $100 \%$, and are the mean values \pm S.E.M. of two different experiments. The significance of the differences was determined using a one-way ANOVA with the Bonferroni post-test: ${ }^{*} P<0.05,{ }^{* *} P<0.01,{ }^{* *} P<0.001$ versus control 


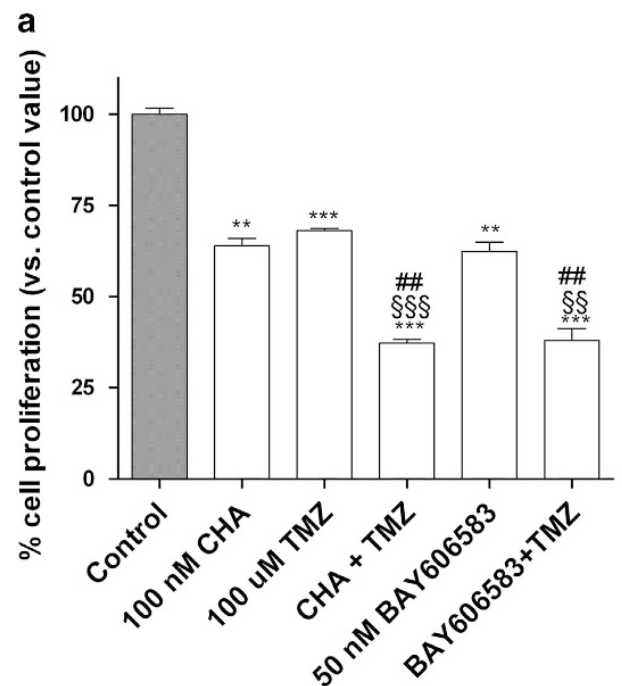

b

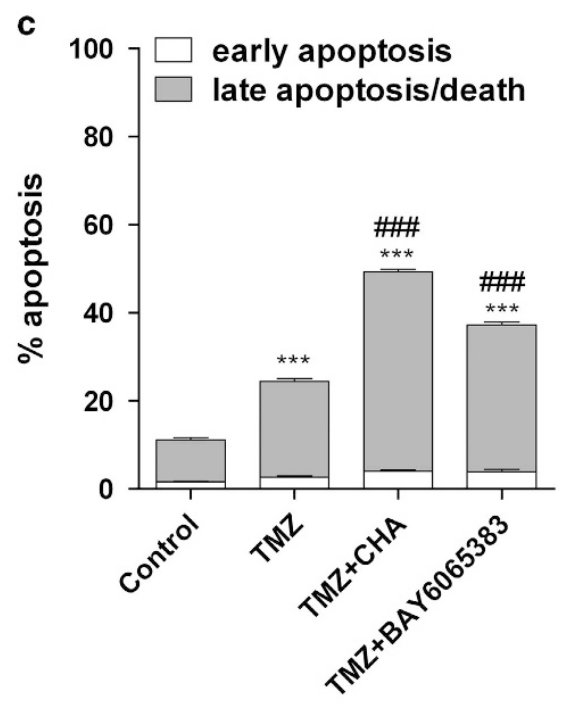

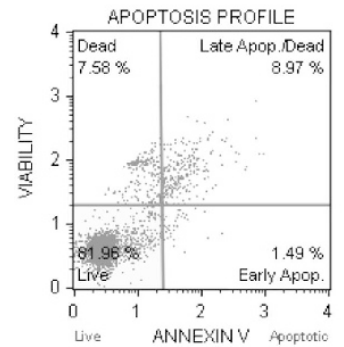

Control

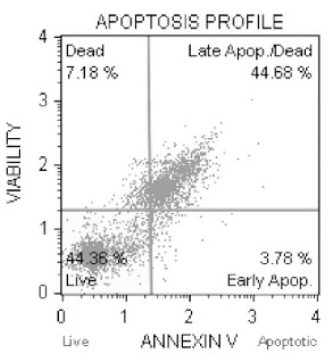

$\mathrm{TMZ}+\mathrm{CHA}$

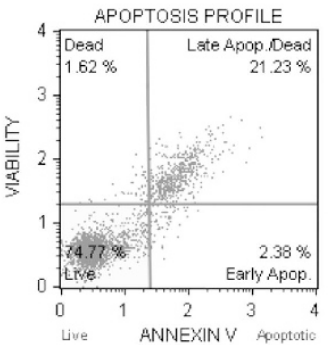

TMZ

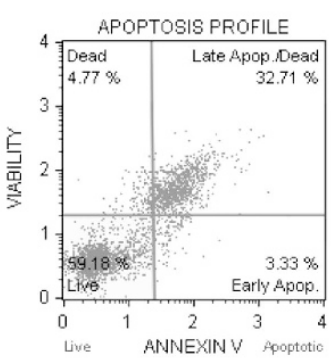

TMZ+BAY606583

Figure 6 Effect of combined treatments with TMZ and an $A_{1} A R$ or $A_{2 B} A R$ agonist on the proliferation and apoptosis of CSCs. (a) U343MG-derived CSCs were incubated for 7 days with $100 \mathrm{nM} \mathrm{CHA}, 50 \mathrm{nM} \mathrm{BAY} 606583$ and $100 \mu \mathrm{M} \mathrm{TMZ}$, alone or in combination. At the end of the treatment periods, cell proliferation was evaluated using the MTS assay. The data were expressed as percentages relative to that of the untreated cells (control), which was set at $100 \%$, and the data shown are the mean values \pm S.E.M. of three independent experiments, each performed in duplicate. The significance of the differences was determined using a one-way ANOVA with the Bonferroni post-test: ${ }^{* *} P<0.01$, ${ }^{* \star \star} P<0.001$ versus control; ${ }^{\# \#} P<0.01$ versus AR agonist alone; ${ }^{\S} P<0.01$, ${ }^{\$ \S} P<0.001$ versus TMZ alone. (b and $\left.\mathbf{c}\right)$ U343MG-derived CSCs were treated as in a. At the end of the treatment periods, the cells were collected and the level of phosphatidylserine externalisation was evaluated using the Annexin V-staining protocol, as described in the Materials and methods section. (c) The data were expressed as the percentage of apoptotic cells (data for the early-stage apoptotic cells shown in white and data for the latestage apoptotic/necrotic cells shown in grey) versus the total number of cells. The data shown are the mean values \pm S.E.M. of three different experiments. The significance of the differences was determined using a one-way ANOVA with the Bonferroni post-test: ${ }^{* \star *} P<0.001$ versus control; ${ }^{\# \# \#} P<0.001$ versus TMZ alone

(CHA: $290 \pm 17 ; \mathrm{CHA}-\mathrm{TMZ}: 220 \pm 17 ; \mathrm{CHA}-\mathrm{TMZ}+$ wash-out: $141 \pm 14$; also see Figures $7 a-d)$. These results suggested that the CHA-differentiated cells had become sensitive to TMZ and that the effect of the sequential treatments were long lasting.

\section{Discussion}

In this study, we found that purinergic receptors for adenosine, and particularly the $A_{1} A R$ and $A_{2 B} A R$ subtypes, had a pivotal role in the survival and/or differentiation of glioblastoma CSCs. 
Stimulation of either the $A_{1} A R$ and $A_{2 B} A R$ had a prominent anti-proliferative effect on the CSCs, and, most importantly, sensitised these cells to the chemotherapeutic activity of TMZ, are as follows: (i) by exerting synergic/addictive effects in promoting cell apoptosis and (ii) by almost completely blocking the ability of cells to resume proliferation.

A
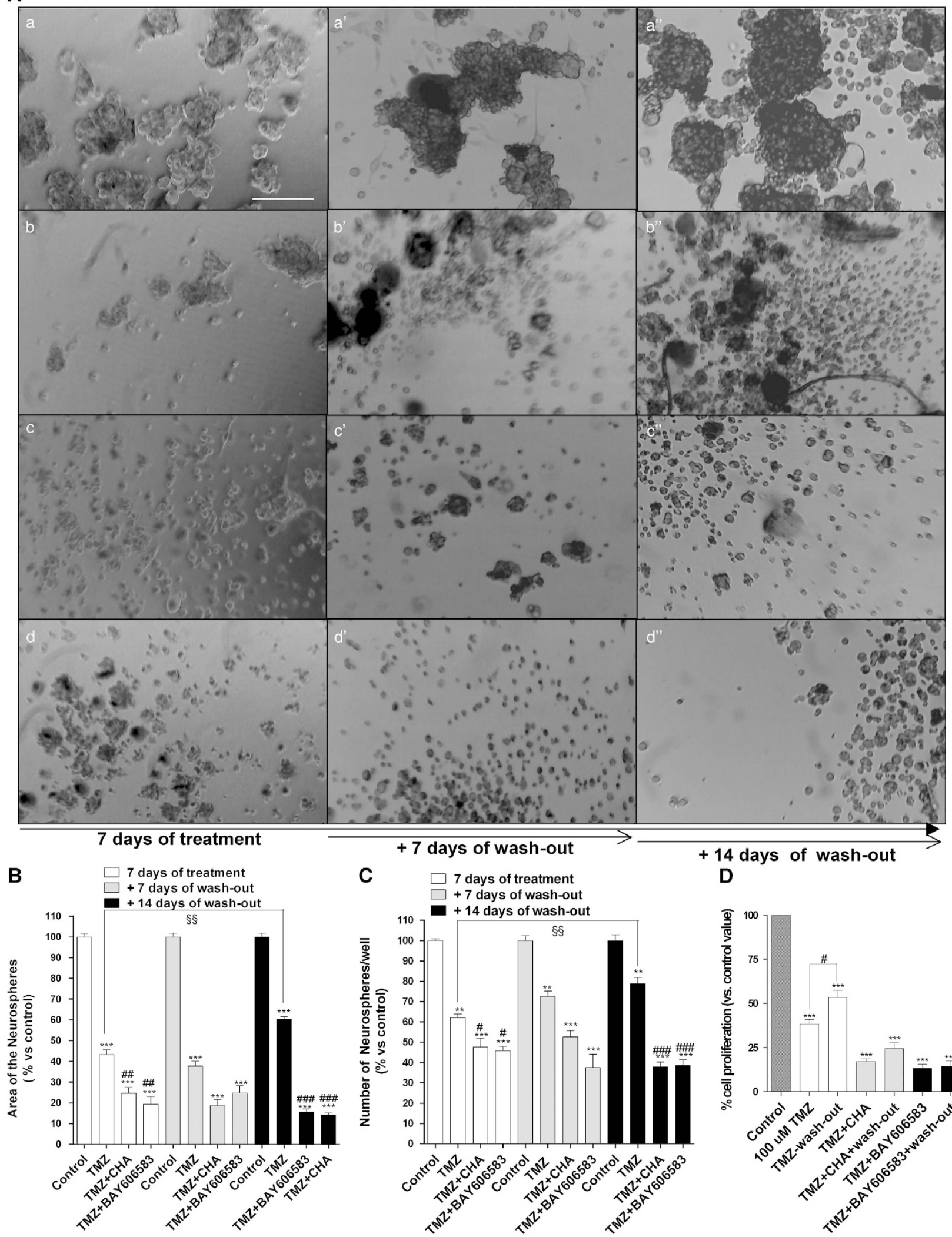

D

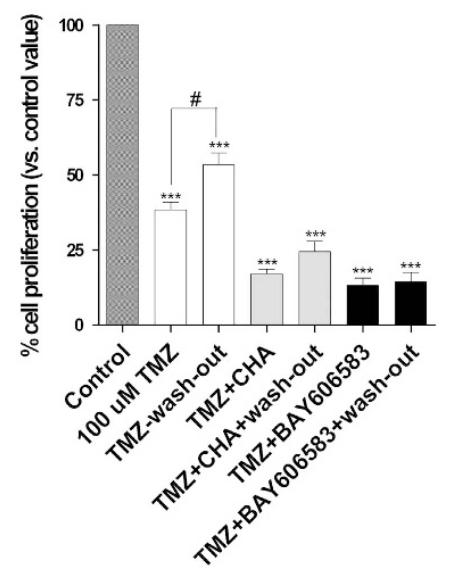


CSCs are responsible for the genesis and recurrence of gliomas and show heightened resistance to irradiation and chemotherapy. ${ }^{24}$ CSCs and normal NSCs share core signalling pathways but also display critical distinctions that provide important clues to useful therapeutic targets. In this respect, one therapeutic strategy specifically directed towards the CSC pool consists of forcing these cells to undergo differentiation. For example, glioma CSCs can be strongly driven toward glial or neuronal differentiation by the use of cannabinoid ligands ${ }^{7}$ or inductors of cell autophagy. ${ }^{56,57}$

In addition to differentiating agents, several inhibitors of neurosphere proliferation have been evaluated. ${ }^{58}$ Appropriate neurotransmission signalling appears to be required for the maintenance of NSCs, and compounds that affect purinergic receptors, among others, affected the formation of spheres of tumour cells. ${ }^{58}$ Therefore, in this study, we focused on the purinergic receptors for adenosine. Each of ARs has indeed a pivotal role in the control of tumour growth and invasiveness ${ }^{30-34}$ but no data on their role in CSC biology are available to date. We showed that in the CSCs derived from GBM cells, selective AR agonists generally reduced the level of cell proliferation/viability after 4-7 days of treatment. The strongest inhibition of cell proliferation was obtained upon stimulation of the $A_{1} A R$ and $A_{2 B} A R$ subtypes.

Then, the morphology and stemness/differentiation of CSCs upon treatment with selective AR agonists were evaluated. BAY606583 caused a reduction in the area occupied by and the number of CSC spheres, and induced a significant level of CSC apoptosis beginning at 4 days of treatment. However, the effects elicited by the $A_{2 B} A R$ agonist were reversible and not long lasting. In contrast, $\mathrm{CHA}$-treated cells showed the prominent outgrowth of cellular processes, with a significant reduction in the levels of the stemness markers and a concomitant increase in the levels of the glial markers. As the $A_{1} A R$ agonist induced CSC apoptosis after 7 days of treatment but not at the 4th day, we speculated that CHA most likely favours the differentiation of CSCs and the subsequent apoptosis of the differentiated cells. At the same time points, $A_{1} A R$ stimulation did not have a significant effect on the proliferation of GBM cells, suggesting that $\mathrm{CHA}$ preferentially depleted the differentiated CSCs rather than GBM cells.

Then, the signalling pathways most likely to be implicated in the CHA- or BAY606583-mediated effects on the proliferation and differentiation of CSCs were investigated. It has been demonstrated that the $\mathrm{PI} 3 \mathrm{~K} / \mathrm{AKT} / \mathrm{mTOR}$ signalling pathway is critical for the maintenance of the properties of glioma CSCs ${ }^{59}$ and that the dual inhibition of PI3K/AKT/mTOR and MEK/ERK signalling induced the differentiation of and inhibited the tumourigenic potential of $\mathrm{CSCs}^{44}$ In this study, we demonstrated that both of the tested $A R$ agonists inhibited the phosphorylation of both ERK1/2 and AKT, but with different kinetic patterns, suggesting that the kinetics of AKT inhibition may explain the differential effects elicited by the two AR agonists.

The two classes of agonists also had different effects on some aspects of HIF transcriptional activity. Both AR agonists decreased the level of HIF-1a transcription at 7 days of treatment, consistent with the data in literature, showing that silencing the HIF-1a gene resulted in the inhibition of GBM tumour growth, by both inhibiting the rate of tumour cell migration/invasion ${ }^{50}$ and inducting CSC differentiation. ${ }^{51,52}$ The $A_{2 B} A R$ ligand did not affect the level of HIF-2a mRNA at the time points used in this study. In contrast, $\mathrm{CHA}$ caused a reduction in the level of HIF-2a expression after 4 days of treatment, and an increase in its level after 7 days of treatment. The initial decrease in HIF-2a expression is consistent with the differentiating properties of $A_{1} A R$; HIF-2 $a$ has been found to be colocalised with stem cell markers in tumour specimens ${ }^{45}$ and to have a pivotal role in maintaining stem cells in an undifferentiated state. ${ }^{60}$ In contrast, the increase in the HIF-2a mRNA levels that was observed on the 7th day may be associated with effects on other signalling pathways in the $\mathrm{CHA}$-differentiated CSCs. For example, the increase in HIF-2a expression that was observed at the latter time point may impair Notch signalling activity, ${ }^{61}$ thus inhibiting cell proliferation and favouring a differentiated cell phenotype. ${ }^{44,62}$

Finally, whether the AR agonists modulated the expression of pro-apoptotic proteins in CSCs was investigated. BAY606583 significantly increased the Bax mRNA levels starting at 4 days of treatment, with a maximal effect at the 7th day. In contrast, $\mathrm{CHA}$ increased Bax transcriptional activity only at the latter time point. These results are consistent with the results obtained in the apoptosis analysis and confirmed that whereas the $A_{2 B} A R$ agonist mainly exerted a proapoptotic effect, CHA first induced CSC differentiation and, in a later phase, triggered the apoptosis of the differentiated cells.

We finally examined the effect of combined treatment with $T M Z$ and the $A_{1} A R$ or $A_{2 B} A R$ ligands on the fate of CSCs. We demonstrated that when the cells were treated with $T M Z$ and BAY606583 or CHA in combination, a synergic/additive effect on the inhibition of CSC proliferation and a significant decrease in the ability of treated cells to resume proliferation was observed. Interestingly, in the presence of TMZ, CHA did not induce CSC differentiation, suggesting that TMZ has a dominant role in driving the cellular fate of CSCs, promoting their apoptosis/death rather than their differentiation.

The most interesting results were obtained in the sequential treatment experiments; challenging cells with the AR agonists

Figure 7 Effect of combined treatments with TMZ and $A_{1} A R$ or $A_{2 B} A R$ agonists on CSC morphology. (A) CSCs were treated for 7 days with complete NSC medium containing DMSO (a), $100 \mu \mathrm{M} \mathrm{TMZ}$ (b) or TMZ in combination with $100 \mathrm{nM} \mathrm{CHA} \mathrm{(c),} \mathrm{or} \mathrm{containing} \mathrm{TMZ} \mathrm{in} \mathrm{combination} \mathrm{with} 50 \mathrm{nM}$ BAY606583 (d). At the end of treatment periods, the drugcontaining media were replaced with fresh drug-free NSC medium, and the cells were cultured for another 7 ( $\left.a^{\prime}, b^{\prime}, c^{\prime}, d^{\prime}\right)$ or 14 (a", b", $\left.c^{\prime \prime}, d^{\prime \prime}\right)$ days. Representative micrographs taken after 7 days of treatment and after 7 or 14 days of drug wash-out are shown $\mathbf{A}$. The area of the culture plates occupied by the spheres (B) and the number of spheres (C) were determined after 7 days of treatment and after 7 and 14 days of drug wash-out. The counts are the mean values \pm S.E.M. of three independent experiments. The significance of the differences was determined using a one-way ANOVA with the Bonferroni post-test: ${ }^{* \star} P<0.05,{ }^{* \star \star} P<0.001$ versus control; ${ }^{\#} P<0.05,{ }^{\# \#} P<0.01,{ }^{\# \# \#} P<0.001$ versus TMZ alone. (D) CSCs were treated as in A and their proliferation was evaluated using the MTS assay. The data were expressed as the percentage relative to that of the untreated cells (control), which was set to $100 \%$, and they are the mean values \pm S.E.M. of three independent experiments, each performed in duplicate. The significance of the differences was determined using a one-way ANOVA with the Bonferroni post-test: ${ }^{* \star} P<0.001$ versus control; ${ }^{\S} P<0.01$ versus cells treated for seven days 


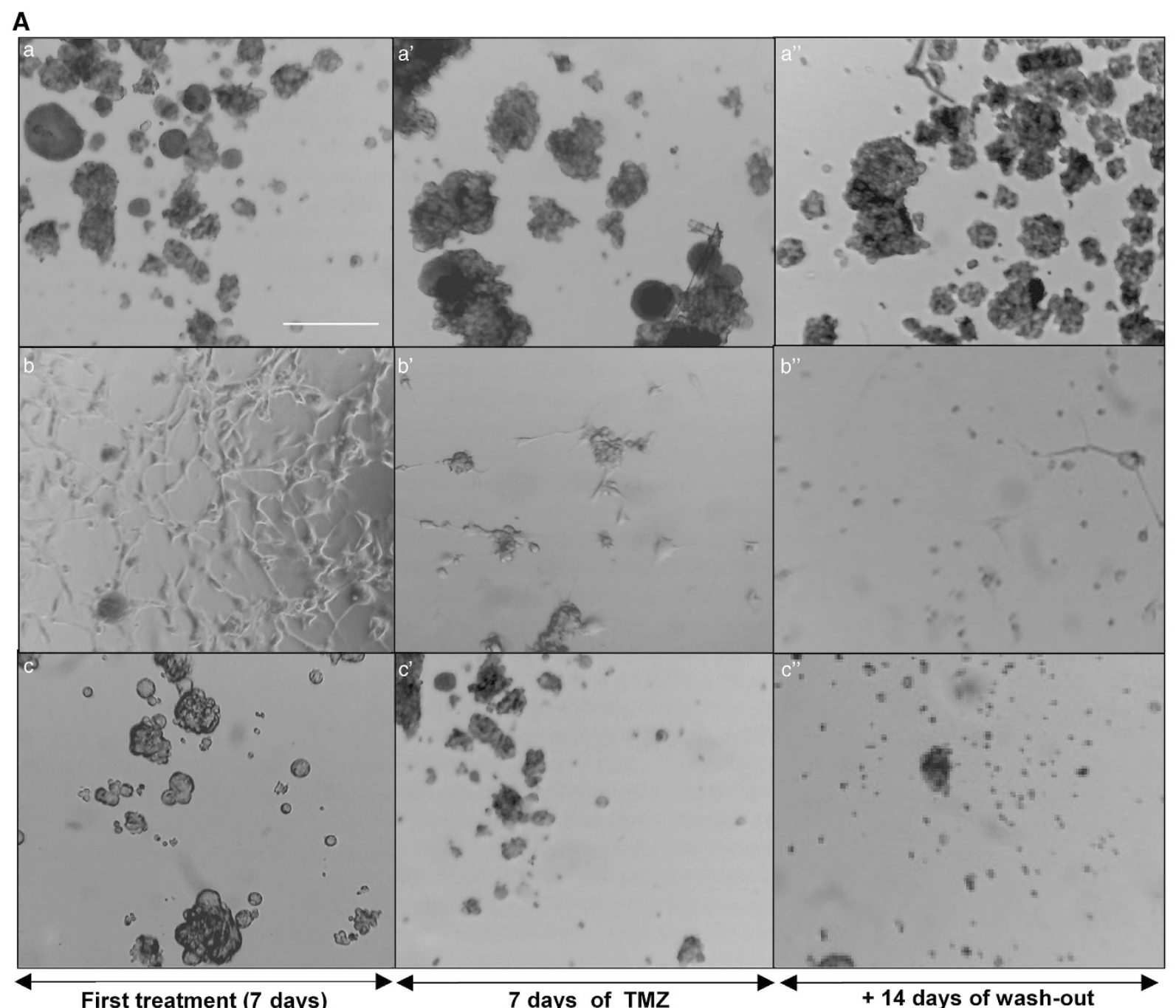

B

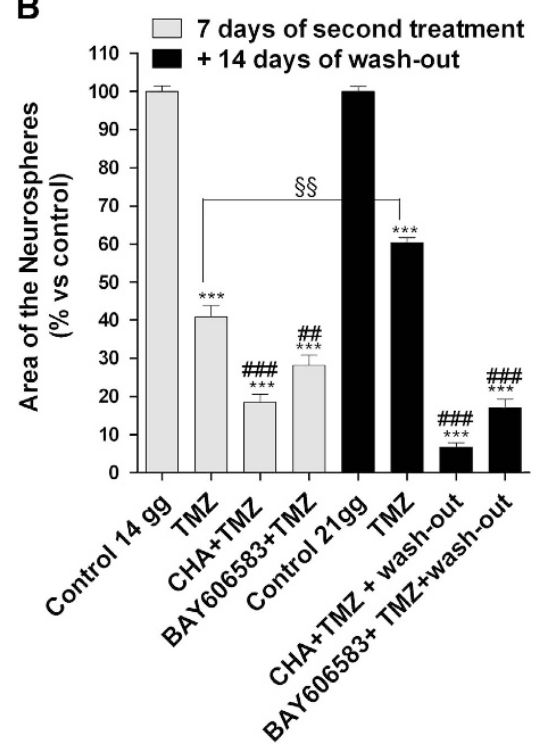

C
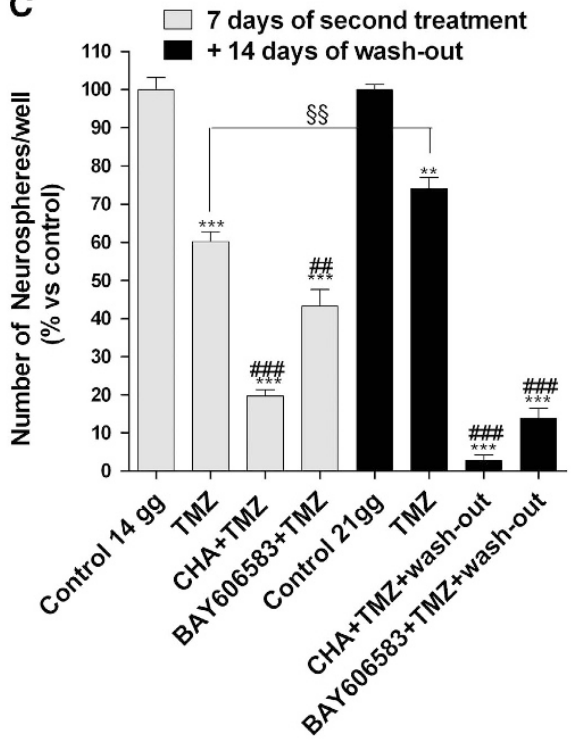

D

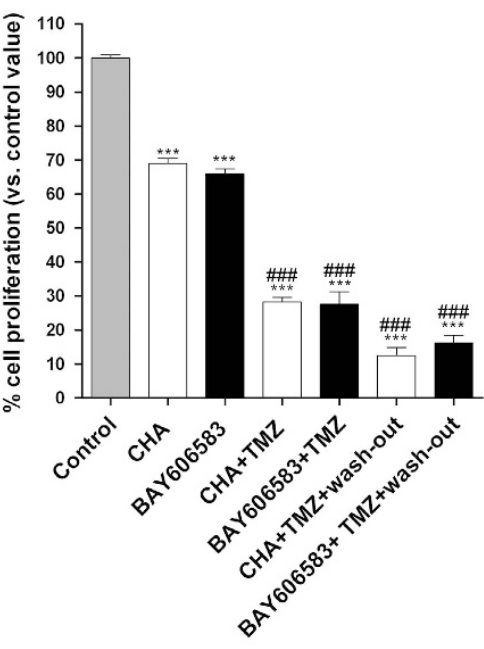


before treating them with $\mathrm{TMZ}$ potentiated the anti-proliferative effects of this chemotherapeutic agent, prolonging its effective period.

These results strongly suggested that modulating the activity of ARs may be an efficient strategy to sensitise glioma CSCs to chemotherapy and that ARs may be invaluable targets in glioma stem cell-orientated therapies.

\section{Materials and Methods}

Materials. $\mathrm{N}^{6}$-cyclo-hexyladenosine (CHA), 3-[4-[2-[[6-amino-9-[(2R,3R,4S,5S)5-(ethylcarbamoyl)-3,4-dihydroxy-oxolan-2-yl]purin-2-yl]amino]ethyl]phenyl]propanoic acid (CGS21680), 2-chloro-N6-(3-iodobenzyl)adenosine- $5^{\prime}-N$-methylcarboxamide (Cl-IB-MECA), 1,3-dipropyl-8-cyclopentylxanthine (DPCPX) and TMZ were purchased from Sigma-Aldrich (Milan, Italy). [2-[6-Amino-3,5-dicyano-4-[4-(cyclopropylmethoxy)-phenyl]jpyridin-2-ylsulfanyl]]acetamide] (BAY606583) and MRS1754 were purchased from Tocris Bioscience (Bristol, UK); the 3-(4,5-dimethylthiazol2-yl)-5-(3-carboxymethoxyphenyl)-2-(4-sulfophenyl)-2H-tetrazolium (MTS) assay kit was obtained from Promega (Milan, Italy). The RNeasy Mini Kit was purchased from Qiagen (Milan, Italy) and the ProtoScript cDNA Synthesis Kit was obtained from Biolabs, Euroclone (Milan, Italy). All of the other reagents that were used were obtained from commercial sources.

GBM cell line culture and CSC isolation. The U87MG and U343MG cell lines were obtained from the National Institute for Cancer Research of Genoa (Italy) and the Cell Lines Service GmbH (Germany), respectively. The DNA profile of each cell line was monitored. The U87MG and U343MG cells were cultured in RPMI medium and Eagle's minimum essential medium adjusted to contain a final concentration of $1.5 \mathrm{~g} / \mathrm{l}$ sodium bicarbonate, respectively, supplemented with $10 \%$ FBS, $2 \mathrm{mM}$ L-glutamine, $100 \mathrm{U} / \mathrm{ml}$ penicillin, $100 \mathrm{mg} / \mathrm{ml}$ streptomycin and $1 \%$ nonessential amino acids at $37^{\circ} \mathrm{C}$ in $5 \% \mathrm{CO}_{2}$. Both cell lines were sub-cultured when the monolayer reached 75 to $85 \%$ confluence, at which point the average cell density was $1.5 \times 10^{5}$ viable cells $/ \mathrm{cm}^{2}$. To isolate CSCs, approximately $2.0 \times 10^{6}$ cells of each GBM cell line was suspended in $1 \mathrm{ml}$ of a defined serum-free NSC medium containing $20 \mathrm{ng} / \mathrm{ml}$ of basic fibroblast growth factor (Sigma-Aldrich), $20 \mathrm{ng} / \mathrm{ml}$ of epidermal growth factor (Sigma-Aldrich) and $20 \mathrm{ng} / \mathrm{ml}$ or $20 \mu \mathrm{l} / \mathrm{ml}$ of B27 supplement (Life Technologies, Milan, Italy). After 3-4 days of culture, the neurospheres were collected, suspended in NSC medium, dissociated into single cells and plated for the assays. For the long-term treatment of cells, NSC or complete medium containing drugs was replaced every 2-3 days.

Cell proliferation/viability assays of GBM cells and CSCs. The human GBM cells or CSCs were seeded at a density of $3 \times 10^{3}$ cells per well. After $24 \mathrm{~h}$, the culture medium was replaced with fresh stem cell culture medium, and the cells were treated for $1-7$ days with the AR agonists CHA $\left(A_{1 A} R\right)$, CGS21680 $\left(A_{2 A} A R\right), B A Y 606583\left(A_{2 B} A R\right)$ and Cl-IB-MECA $\left(A_{3} A R\right)$ at different concentrations, and with $T M Z$, alone or in combination. Following the treatment period, cell proliferation was using the MTS assay according to manufacturer's instructions. In some experiments, the effects of the AR antagonists on agonist-mediated effects were evaluated. In particular, the $A_{1 A} R$ antagonist DPCPX ( $50 \mathrm{nM}$ ) and the $A_{2 B} A R$ antagonist MRS1754 $(20 \mathrm{nM})$ were used. The antagonists were added $10 \mathrm{~min}$ before the addition of $100 \mathrm{nM}$ CHA or $50 \mathrm{nM}$ BAY606583, respectively.

For the drug wash-out experiments, neurospheres were treated for 7 days with $100 \mathrm{nM} \mathrm{CHA}, 50 \mathrm{nM}$ BAY606583, and $100 \mu \mathrm{M} \mathrm{TMZ}$, alone or in combination. For sequential treatments, the cells were pre-treated with AR agonists for 7 days and then with TMZ for another 7 days. At the end of treatment periods, the drug-containing media were replaced with fresh drug-free NSC medium, and the cells were allowed to grow for another 14 days.

Within an experiment, each condition was assayed in triplicate, and each experiment was performed at least three times. The results were calculated by subtracting the mean background values from the values obtained under each test condition and were expressed as the percentages of the control (untreated cells) values.

The effects of the combined treatments on CSC viability were also evaluated using the Trypan blue exclusion assay. U87MG-derived CSCs were treated for 1-7 days with CHA, CGS21680, BAY606583 and CI-IBMECA at the indicated concentrations and with $\operatorname{TMZ}(100 \mu \mathrm{M})$, alone or in combination. Following the treatment period, cells were collected and centrifuged at $300 \times g$ for $5 \mathrm{~min}$. The harvested cells were mixed with an equal volume of $0.4 \%$ Trypan blue dye, and the blue (dead cells) and white (living cells) cells in each well were manually counted. The number of live cells for each condition was reported as the percentage of living cells relative to that in the control sample.

$\left[{ }^{35}\right.$ S $]$ GTPyS-binding assay in CSCs. $\left[{ }^{35}\right.$ S GTP $\gamma$ S binding to membranes obtained from CSCs was assayed as previously described, with some modifications. ${ }^{63}$ Briefly, cell membranes $(30 \mu \mathrm{g})$ obtained from U343MG-derived CSCs were incubated in the assay buffer $(50 \mathrm{mM}$ Tris- $\mathrm{HCl}, 1 \mathrm{mM}$ EDTA, $1 \mathrm{mM}$ $\mathrm{MgCl}_{2}, 100 \mathrm{mM} \mathrm{NaCl}, 1 \mathrm{mM}$ DL-dithiothreitol, $0.0005 \%$ Tween 20 and $0.5 \%$ bovine serum albumin) in the presence of 2 units/ml adenosine deaminase, $1 \mu \mathrm{M}$ GDP and the AR agonists at different concentrations. Binding was initiated by the addition of $0.2 \mathrm{nM}\left[{ }^{35} \mathrm{~S}\right] \mathrm{GTP} \gamma \mathrm{S}$ and the incubation was continued for $30 \mathrm{~min}$ at $25^{\circ} \mathrm{C}$. The level of nonspecific binding was determined using $10 \mu \mathrm{M}$ unlabelled GTP $\gamma$ S. The reaction was stopped by rapid filtration and the plates were washed twice using $200 \mu \mathrm{l}$ of buffer. The levels of radioactivity were measured using liquid scintillation spectrometry.

Western blot analysis. CSCs were treated with DMSO (control), $100 \mathrm{nM}$ $\mathrm{CHA}$ or $50 \mathrm{nM}$ BAY 606583 for 7 days. At the end of the treatment period, the cells were collected and then were lysed for $60 \mathrm{~min}$ at $4{ }^{\circ} \mathrm{C}$ using $200 \mu \mathrm{l}$ of RIPA buffer (9.1 mM NaH $2 \mathrm{PO}_{4}, 1.7 \mathrm{mM} \mathrm{Na}_{2} \mathrm{HPO}_{4}, 150 \mathrm{mM} \mathrm{NaCl}, \mathrm{pH} 7.4,0.5 \%$ sodium deoxycholate, $1 \%$ Nonidet P-40, $0.1 \%$ SDS and a protease-inhibitor cocktail). Equal amounts of the cell extracts ( $40 \mu \mathrm{g}$ of protein) were diluted in Laemmli sample solution, resolved using SDS-PAGE (8.5\%), transferred to PVDF membranes and probed overnight at $4{ }^{\circ} \mathrm{C}$ using the following primary antibodies: anti-nestin (sc20978, Santa Cruz Biotechnology, Heidelberg, Germany; 1:50); anti-GFAP (sc9065, Santa Cruz Biotechnology; 1:50); anti- $A_{1 A} R$ (sc-19223, Santa Cruz Biotechnology; 1:200), anti- $A_{2 A} A R$ (sc-13937, Santa Cruz Biotechnology; 1:200); anti- $A_{2 B} A R$ (sc-28996, Santa Cruz Biotechnology; 1:50); anti- $A_{3} A R$ (sc-13938, Santa Cruz Biotechnology; 1:200); and anti-caspase-3 (sc-7148, Santa Cruz Biotechnology; 1:100). The primary antibodies were detected using the appropriate peroxidase-conjugated secondary antibodies, which were then detected using a chemioluminescent substrate (ECL, Perkin Elmer, Waltham, MA, USA). Densitometric analysis of the immunoreactive bands was performed using ImageJ Software (version 1.41; Bethesda, MD, USA).

Quantitation of the occupied area and the cellular processes of neurospheres. CSCs isolated from U343MG cells were plated in NSC medium

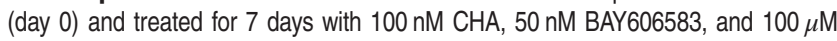
TMZ, alone or in combination (until day 7). In some experiments, the CSCs were treated with the indicated AR agonist (until day 7), and subsequently with TMZ for another 7 days (until day 14). At the end of the treatment periods, the drugcontaining media were replaced with fresh NSC medium, and the CSCs were allowed to grow for another 7 or 14 days. Photographs of the neurospheres were

Figure 8 Effect of the sequential treatment of CSCs with an $A_{1} A R$ or $A_{2 B} A R$ agonist and TMZ on their morphology. (A) CSCs were treated for 7 days with complete NSC medium containing DMSO (control) (a), $100 \mathrm{nM} \mathrm{CHA} \mathrm{(b)} \mathrm{or} 50 \mathrm{nM}$ BAY606583 (c); after 7 days, the cells were treated for another 7 days with complete NSC medium containing DMSO (a') or $100 \mu \mathrm{M} \mathrm{TMZ}\left(\mathrm{b}^{\prime}, \mathrm{c}^{\prime}\right)$. At the end of treatment periods, the drug-containing media were replaced with fresh drug-free NSC medium, and the cells were cultured for another 14 days $\left(a^{\prime \prime}, b^{\prime \prime}, c^{\prime \prime}\right)$. Representative micrographs taken after 7 days of treatment and after 7 or 14 days of drug wash-out are shown $\mathbf{A}$. The area of the culture plates occupied by the spheres (B) and the number of spheres (C) were determined after 7 days of treatment and after 7 and 14 days of drug wash-out. The counts are the mean values \pm S.E.M. of three independent experiments. The significance of the differences was determined using a one-way ANOVA with the Bonferroni post-test: ${ }^{* *} P<0.01$, ${ }^{* * \star} P<0.001$ versus control; ${ }^{\#} P<0.01,{ }^{\# \#} P<0.001$ versus TMZ alone. (D) CSCs were treated as in $A$ and their proliferation was evaluated using the MTS assay. The data were expressed as the percentages relative to that of the untreated cells (control), which was set at $100 \%$, and they are the mean values \pm S.E.M. of three independent experiments, each performed in duplicate. The significance of the differences was determined using a one-way ANOVA with the Bonferroni post-test: ${ }^{* * \star} P<0.001$ versus control; \#\#\# $P<0.001$ versus single-agent-treated cells. ${ }^{\text {}}{ }^{\circledR} P<0.01$ versus cells treated for seven days with TMZ 
taken at days $0,7,14$ and 21; three different wells were analysed for each condition, 15 images of each well were captured (using a $20 \times$ objective lens). The response of the cultures to the various treatments was quantified by measuring the area occupied by neurospheres that had formed, using the ImageJ program. The cellular processes extending from the six to eight differentiating neurospheres per condition in three independent experiments were evaluated. To measure the cellular processes, the average diameter of an individual neurosphere in the vertical and horizontal planes was determined. The number of extensions from the body of the neurospheres was counted, and the ratio of the number of extensions to the average neurosphere diameter was calculated. ${ }^{64}$ In addition, the neurite lengths were measured. All of the measurements were performed using the ImageJ Program (http://rsbweb.nih.gov/ij/docs/faqs.html\#cite).

RNA extraction and real-time PCR analysis. CSCs were treated with proliferation medium containing DMSO (control), CHA, CGS21680, BAY606583 or Cl-IBMECA at the indicated concentrations or TMZ for 4 or 7 days. At the end of the treatment period, the cells were collected, and total RNA was extracted using RNeasy Mini Kit (Qiagen, Hilden, Germany) according to manufacturer's instructions. The purity of the RNA samples was evaluated by measuring the absorbance at 260 and $280 \mathrm{~nm}$. cDNA synthesis was performed with $500 \mathrm{ng}$ of RNA using the i-Script cDNA synthesis kit (Bio-Rad, Hercules, CA, USA) according to the manufacturer's instructions. The primers used for RT-PCR were designed to anneal to the intron/exon boundaries to ensure that the amplified products did not include genomic DNA. The RT-PCR reaction mixtures consisted of $25 \mu$ l of Fluocycle II SYBR (Euroclone), $1.5 \mu \mathrm{l}$ of $10 \mu \mathrm{M}$ forward and reverse primers, $3 \mu \mathrm{l}$ of cDNA, and $19 \mu \mathrm{l}$ of $\mathrm{H}_{2} \mathrm{O}$. All of the reactions were performed for 40 cycles using the following temperature profile: $98^{\circ} \mathrm{C}$ for $30 \mathrm{~s}$ (initial denaturation); $\mathrm{T}^{\circ} \mathrm{C}$ (see Supplementary Table 1) for $30 \mathrm{~s}$ (annealing); and $72{ }^{\circ} \mathrm{C}$ for $3 \mathrm{~s}$ (extension). $\beta$-Actin was used as the housekeeping gene. The levels of mRNA in each sample were normalised against the level of $\beta$-actin mRNA, and the relative expression was calculated using the $\mathrm{Ct}$ value. The specificity of the assays was determined by both melting curve analysis and gel electrophoresis, and the data were analysed using the standard-curve method. For the quantitation of $A R$ expression in CSCs, the data were expressed as the fold change relative to the level of expression of each AR subtype in whole GBM cells.

Annexin V and 7-AAD staining. Dual staining with Annexin $\mathrm{V}$ conjugated to fluorescein-isothiocyanate (FITC) and 7-amino-actinomysin (7-AAD) was performed using a commercially available kit (Muse Annexin V and Dead Cell Kit; Merck KGaA, Darmstadt, Germany). Briefly, CSCs were treated with DMSO (control), $100 \mathrm{nM}$ CHA, $500 \mathrm{nM}$ CGS21680, $50 \mathrm{nM}$ BAY606583, $5 \mathrm{nM}$ Cl-IBMECA or $100 \mu \mathrm{M}$ TMZ, alone or in combination, for 4 or 7 days. Both the floating and adherent cells were collected, centrifuged at $300 \times g$ for $5 \mathrm{~min}$ and suspended in cell culture medium. Then, a $100 \mu \mathrm{l}$ aliquot of the cell suspension (approximately $5 \times 10^{4} \mathrm{cell} / \mathrm{ml}$ ) was added to $100 \mu \mathrm{l}$ of fluorescent reagent and incubated for $10 \mathrm{~min}$ at room temperature. Subsequently, the percentages of living, apoptotic and dead cells were determined using a Muse Cell Analyzer in accordance to the manufacturer's guidelines. In cells undergoing apoptosis, Annexin $\mathrm{V}$ binds to phosphatidylserine, which is translocated from the inner to the outer leaflet of the cytoplasmic membrane. Double staining was used to distinguish the viable, early-stage apoptotic, and necrotic or late-stage apoptotic cells. Annexin V-FITC-positive and/7AAD-positive cells were identified as in the early apoptotic stage. Cells that were Annexin V-FITC positive and 7-AAD positive were identified as cells in late-stage apoptosis or as necrotic cells, respectively.

ERK and AKT phosphorylation assays. CSCs isolated from U87MG cells were collected and were treated for 5 or 30 min with DMSO, $100 \mathrm{nM} \mathrm{CHA} \mathrm{or}$ $50 \mathrm{nM}$ BAY606583. At the end of the treatment period, the CSCs were centrifuged at $500 \times g$ for $3 \mathrm{~min}$, washed twice using fresh saline, and then were rapidly fixed using $8 \%$ formaldehyde to preserve specific modified proteins in the activated state. The levels of total and phosphorylated AKT and ERK $1 / 2$ were determined using Fast Activated Cell-Based ELISA Kits (Active Motif, Carlsbad, CA, USA), using specific primary antibodies. The subsequent incubation with a secondary HRPconjugated antibody and the developing solution allowed the colorimetric quantification of the levels of total and phosphorylated proteins. The relative number of cells in each well was then determined using the Crystal-Violet assay. The results were calculated by subtracting the mean background value from the values obtained under each test condition: values were normalised to the number of cells in each well and were expressed as the percentages of the control (untreated cells) values.
Statistical analyses. The nonlinear multipurpose curve-fitting program GraphPad Prism (GraphPad Software Inc., San Diego, CA, USA) was used to analyse the data and prepare the graphic presentations. All of the data were expressed as the mean values \pm S.E.M. The data were analysed using a one-way analysis of variance (ANOVA) with Bonferroni's corrected t-test for post-hoc pair-wise comparisons. $P<0.05$ was considered statistically significant.

\section{Conflict of Interest}

The authors declare no conflict of interest.

Acknowledgements. We thank Dr. Chiara Giacomelli for the cell apoptosis analysis.

1. Dolecek TA, Propp JM, Stroup NE, Kruchko C. CBTRUS statistical report: primary brain and central nervous system tumors diagnosed in the United States in 2004-2008. Neuro-Oncology 2012; 14: 1-49.

2. Legler JM, Ries LA, Smith MA, Warren JL, Heineman EF, Kaplan R et al. Cancer surveillance series (corrected): brain and other central nervous system cancers: recent trends in incidence and mortality. J Natl Cancer Inst 1999; 91: 1382-1390.

3. Wen PY, Kesari S. Malignant gliomas in adults. N Engl J Med 2008; 359: 492-507.

4. Eramo A, Ricci-Vitiani L, Zeuner A, Pallini R, Lotti F, Sette G et al. Chemotherapy resistance of glioblastoma stem cells. Cell Death Differ 2006; 13: 1238-1241.

5. Smalley M, Piggott L, Clarkson R. Breast cancer stem cells: obstacles to therapy. Cancer Lett 2013; 338: 57-62.

6. Van Rhenen A, Feller N, Kelder A, Westra AH, Rombouts E, Zweegman S et al. High stem cell frequency in acute myeloid leukemia at diagnosis predicts high minimal residual disease and poor survival. Clin Cancer Res 2005; 11: 6520-6527.

7. Aguado T, Carracedo A, Julien B, Velasco G, Milman G, Mechoulam R et al. Cannabinoids induce glioma stem-like cell differentiation and inhibit gliomagenesis. J Biol Chem 2007; 282: $6854-6862$.

8. Ahmed N, Salsman VS, Kew Y, Shaffer D, Powell S, Zhang YJ et al. HER2-specific T cells target primary glioblastoma stem cells and induce regression of autologous experimental tumors. Clin Cancer Res 2010; 16: 474-485.

9. Aloy MT, Hadchity E, Bionda C, Diaz-Latoud C, Claude L, Rousson R et al. Protective role of Hsp27 protein against gamma radiation-induced apoptosis and radiosensitization effects of Hsp27 gene silencing in different human tumor cells. Int J Radiat Oncol Biol Phys 2008; 70: 543-553.

10. Altaner C. Glioblastoma and stem cells. Neoplasma 2008; 55: 369-374.

11. Balyasnikova IV, Franco-Gou R, Mathis JM, Lesniak MS. Genetic modification of mesenchymal stem cells to express a single-chain antibody against EGFRvIll on the cell surface. J Tissue Eng Regen Med 2010; 4: 247-258.

12. Bar EE, Chaudhry A, Lin A, Fan X, Schreck K, Matsui W et al. Cyclopamine-mediated hedgehog pathway inhibition depletes stem-like cancer cells in glioblastoma. Stem Cells 2007; 25: 2524-2533.

13. Chalmers AJ. Radioresistant glioma stem cells- therapeutic obstacle or promising target? DNA Repair 2007; 6: 1391-1394.

14. Cho DY, Lin SZ, Yang WK, Hsu DM, Lin HL, Lee HC et al. The role of cancer stem cells (CD133(+)) in malignant gliomas. Cell Transplant 2011; 20: 121-125.

15. Fan X, Salford LG, Widegren B. Glioma stem cell: evidence and limitation. Semin Cancer Biol 2007; 17: 214-218.

16. Gadji M, Crous AM, Fortin D, Krcek J, Torchia M, Mai S et al. EGF receptor inhibitors in the treatment of glioblastoma multiform: old clinical allies and newly emerging therapeutic concepts. Eur J Pharmacol 2009; 625: 23-30.

17. Hughes SA, Achanta P, Ho AL, Duenas VJ, Quiñones-Hinojosa A. Biological horizons for targeting brain malignancy. Adv Exp Med Biol 2010; 671: 93-104.

18. Rappa G, Mercapide J, Anzanello F, Prasmickaite L, Xi Y, Ju J et al. Growth of cancer cell lines under stem cell-like conditions has the potential to unveil therapeutic targets. Exp Cell Res 2008; 314: 2110-2122.

19. Diehn M, Cho RW, Lobo NA, Kalisky T, Dorie MJ, Kulp AN et al. Association of reactive oxygen species levels and radioresistance in cancer stem cells. Nature 2009; 458 : 780-783.

20. Bao S, Wu Q, McLendon RE, Hao Y, Shi Q, Hjelmeland AB et al. Glioma stem cells promote radioresistance by preferential activation of the DNA damage response. Nature 2006; 444 756-760.

21. Yu SC, Ping YF, Yi L, Zhou ZH, Chen JH, Yao XH et al. Isolation and characterization of cancer stem cells from a human glioblastoma cell line U87. Cancer Lett 2008; 265: 124-134.

22. Qiang L, Yang Y, Ma YJ, Chen FH, Zhang LB, Liu W et al. Isolation and characterization of cancer stem like cells in human glioblastoma cell lines. Cancer Lett 2009; 279: 13-21.

23. Beier D, Röhrl S, Pillai DR, Schwarz S, Kunz-Schughart LA, Leukel P et al. Temozolomide preferentially depletes cancer stem cells in glioblastoma. Cancer Res 2008; 68: 5706-5715

24. Beier D, Schulz JB, Beier CP. Chemoresistance of glioblastoma cancer stem cells-much more complex than expected. Mol Cancer 2011; 10: 128-138. 
25. Happold C, Roth P, Wick W, Schmidt N, Florea AM, Silginer M et al. Distinct molecular mechanisms of acquired resistance to temozolomide in glioblastoma cells. $J$ Neurochem 2012; 122: 444-455.

26. Morrone FB, Jacques-Silva MC, Horn AP, Bernardi A, Schwartsmann G, Rodnight R et al. Extracellular nucleotides and nucleosides induce proliferation and increase nucleoside transport in human glioma cell lines. J Neurooncol 2003; 64: 211-218.

27. Wei W, Ryu JK, Choi HB, McLarnon JG. Expression and function of the p2x(7) receptor in rat c6 glioma cells. Cancer Lett 2008; 260: 79-87.

28. Gessi S, Sacchetto V, Fogli E, Merighi S, Varani K, Baraldi PG et al. Modulation of metalloproteinase-9 in U87MG glioblastoma cells by A3 adenosine receptors. Biochem Pharmacol 2010; 79: 1483-1495.

29. Morrone FB, Horn AP, Stella J, Spiller F, Sarkis JJ, Salbego CG et al. Increased resistance of glioma cell lines to extracellular ATP cytotoxicity. J Neurooncol 2005; 71: 135-140.

30. Fredholm BB, ljzerman AP, Jacobson KA, Linden J, Müller CE. International Union of Basic and Clinical Pharmacology. LXXXI. Nomenclature and classification of adenosine receptors - an update. Pharmacol Rev 2011; 63: 1-34.

31. Merighi S, Mirandola P, Varani K, Gessi S, Leung E, Baraldi PG et al. A glance at adenosine receptors: novel target for antitumor therapy. Pharmacol Ther 2003; 100: 31-48.

32. Gessi S, Merighi S, Varani K, Leung E, Mac Lennan S, Borea PA. The A3 adenosine receptor: an enigmatic player in cell biology. Pharmacol Ther 2008; 117: 123-140.

33. Ledur PF, Villodre ES, Paulus R, Cruz LA, Flores DG, Lenz G. Extracellular ATP reduces tumor sphere growth and cancer stem cell population in glioblastoma cells. Purinergic Signal 2012; 8: 39-48.

34. Gessi S, Merighi S, Sacchetto V, Simioni C, Borea PA. Adenosine receptors and cancer. Biochim Biophys Acta 2011; 1: 1400-1412.

35. Piccirillo SG, Reynolds BA, Zanetti N, Lamorte G, Binda E, Broggi G et al. Bone morphogenetic proteins inhibit the tumorigenic potential of human brain tumourinitiating cells. Nature 2006; 444: 761-765.

36. Castillo CA, León D, Ruiz MA, Albasanz JL, Martín M. Modulation of adenosine A1 and A2A receptors in C6 glioma cells during hypoxia: involvement of endogenous adenosine. J Neurochem 2008; 105: 2315-2329.

37. Castillo CA, Albasanz JL, Fernández M, Martín M. Endogenous expression of adenosine A1, A2 and A3 receptors in rat C6 glioma cells. Neurochem Res 2007; 32: 1056-1070.

38. Marteau F, Le Poul E, Communi D, Communi D, Labouret C, Savi P et al. Pharmacological characterization of the human P2Y13 receptor. Mol Pharmacol 2003; 64 : 104-112.

39. Dhalla AK, Shryock JC, Shreeniwas R, Belardinelli L. Pharmacology and therapeutic applications of A1 adenosine receptor ligands. Curr Top Med Chem 2003; 3: 369-385.

40. Ortore $G$, Martinelli $A . A_{2 B}$ receptor ligands: past, present and future trends. Curr Top Med Chem 2010; 10: 923-940.

41. Luthin DR, Olsson RA, Thompson RD, Sawmiller DR, Linden J. Characterization of two affinity states of adenosine A2a receptors with a new radioligand, 2-[2-(4-amino-3-[125I] iodophenyl) ethylamino]adenosine. Mol Pharmacol 1995; 47: 307-313.

42. Lim MH, Kim HO, Moon HR, Lee SJ, Chun MW, Gao ZG et al. Design, synthesis and binding affinity of 3'-fluoro analogues of CI-IB-MECA as adenosine A3 receptor ligands. Bioorg Med Chem Lett 2003; 13: 817-820.

43. Cho DY, Lin SZ, Yang WK, Lee HC, Hsu DM, Lin HL et al. Targeting cancer stem cells for treatment of glioblastoma multiforme. Cell Transplant 2013; 22: 731-739.

44. Sunayama J, Matsuda K, Sato A, Tachibana K, Suzuki K, Narita Y et al. Crosstalk between the PI3K/mTOR and MEK/ERK pathways involved in the maintenance of self-renewal and tumorigenicity of glioblastoma stem-like cells. Stem Cells 2010; 28: 1930-1939.

45. Li Z, Bao S, Wu Q, Wang H, Eyler C, Sathornsumetee $\mathrm{S}$ et al. Hypoxia-inducible factors regulate tumorigenic capacity of glioma stem cells. Cancer Cell 2009; 15: 501-513.

46. Platet N, Liu SY, Atifi ME, Oliver L, Vallette FM, Berger F et al. Influence of oxygen tension on CD133 phenotype in human glioma cell cultures. Cancer Lett 2007; 258: 286-290.

47. Gilbertson RJ, Rich JN. Making a tumour's bed: glioblastoma stem cells and the vascular niche. Nat Rev Cancer 2007: 7: 733-736.
48. McCord AM, Jamal M, Shankavaram UT, Lang FF, Camphausen K, Tofilon PJ. Physiologic oxygen concentration enhances the stem-like properties of CD133+ human glioblastoma cells in vitro. Mol Cancer Res 2009; 7: 489-497.

49. Soeda A, Park M, Lee D, Mintz A, Androutsellis-Theotokis A, McKay RD et al. Hypoxia promotes expansion of the CD133-positive glioma stem cells through activation of HIF-1alpha. Oncogene 2009; 28: 3949-3959.

50. Bar EE, Lin A, Mahairaki V, Matsui W, Eberhart CG. Hypoxia increases the expression of stem-cell markers and promotes clonogenicity in glioblastoma neurospheres. Am J Pathol 2010; 177: 1491-1502.

51. Méndez O, Zavadil J, Esencay M, Lukyanov Y, Santovasi D, Wang SC et al. Knock down of HIF-1alpha in glioma cells reduces migration in vitro and invasion in vivo and impairs their ability to form tumor spheres. Mol Cancer 2010; 9: 133.

52. Blum R, Jacob-Hirsch J, Amariglio N, Rechavi G, Kloog Y. Ras inhibition in glioblastoma down-regulates hypoxia-inducible factor-1alpha, causing glycolysis shutdown and cell death. Cancer Res 2005; 65: 999-1006.

53. Tait SW, Green DR. Mitochondria and cell death: outer membrane permeabilization and beyond. Nat Rev Mol Cell Biol 2010; 11: 621-632

54. Timmer JC, Salvesen GS. Caspase substrates. Cell Death Differ 2007; 14: 66-72.

55. Johannessen TC, Prestegarden L, Grudic A, Hegi ME, Tysnes BB, Bjerkvig R. The DNA repair protein $\mathrm{ALKBH} 2$ mediates temozolomide resistance in human glioblastoma cells. Neuro-Oncology 2013; 15: 269-278.

56. Zhuang W, Long L, Zheng B, Ji W, Yang N, Zhang Q et al. Curcumin promotes differentiation of glioma-initiating cells by inducing autophagy. Cancer Sci 2012; 103: 684-690.

57. Zhuang W, Li B, Long L, Chen L, Huang Q, Liang Z. Induction of autophagy promotes differentiation of glioma-initiating cells and their radiosensitivity. Int J Cancer 2011; 129: 2720-2731.

58. Diamandis P, Wildenhain J, Clarke ID, Sacher AG, Graham J, Bellows DS et al. Chemical genetics reveals a complex functional ground state of neural stem cells. Nat Chem Biol 2007; 3: 268-273.

59. Sunayama J, Sato A, Matsuda K, Tachibana K, Suzuki K, Narita Y et al. Dual blocking of mTor and PI3K elicits a prodifferentiation effect on glioblastoma stem-like cells. Neuro Oncol 2010; 12: 1205-1219.

60. Pietras A, Hansford LM, Johnsson AS, Bridges E, Sjölund J, Gisselsson D et al. HIF-2alpha maintains an undifferentiated state in neural crest-like human neuroblastoma tumorinitiating cells. Proc Natl Acad Sci USA 2009; 106: 16805-16810.

61. Hu YY, Fu LA, Li SZ, Chen Y, Li JC, Han J et al. Hif-1 $\alpha$ and Hif-2 $\alpha$ differentially regulate Notch signaling through competitive interaction with the intracellular domain of Notch receptors in glioma stem cells. Cancer Lett 2014; 349: 67-76.

62. Gaiano N, Fishell G. The role of notch in promoting glial and neural stem cell fates. Annu Rev Neurosci 2002; 25: 471-490.

63. Gao ZG, Ye K, Göblyös A, ljzerman AP, Jacobson KA. Flexible modulation of agonist efficacy at the human A3 adenosine receptor by the imidazoquinoline allosteric enhancer LUF6000. BMC Pharmacol 2008; 8: 20-30

64. Fernando $P$, Brunette $S$, Megeney LA. Neural stem cell differentiation is dependent upon endogenous caspase 3 activity. FASEB J 2005; 19: 671-673.

(i) Cell Death and Disease is an open-access journal published by Nature Publishing Group. This work is licensed under a Creative Commons Attribution 4.0 International Licence. The images or other third party material in this article are included in the article's Creative Commons licence, unless indicated otherwise in the credit line; if the material is not included under the Creative Commons licence, users will need to obtain permission from the licence holder to reproduce the material. To view a copy of this licence, visit http://creativecommons.org/licenses/by/4.0 